\title{
Maturation of EPSCs and Intrinsic Membrane Properties Enhances Precision at a Cerebellar Synapse
}

\author{
Laurence Cathala, Stephen Brickley, Stuart Cull-Candy, and Mark Farrant \\ Department of Pharmacology, University College London, London WC1E 6BT, United Kingdom
}

The timing of action potentials is an important determinant of information coding in the brain. The shape of the EPSP has a key influence on the temporal precision of spike generation. Here we use dynamic clamp recording and passive neuronal models to study how developmental changes in synaptic conductance waveform and intrinsic membrane properties combine to affect the EPSP and action potential generation in cerebellar granule cells. We recorded EPSCs at newly formed and mature mossy fiber-granule cell synapses. Both quantal and evoked currents showed a marked speeding of the AMPA receptor-mediated component. We also found evidence for age- and activity-dependent changes in the involvement of NMDA receptors. Although AMPA and NMDA receptors contributed to quantal EPSCs at immature synapses, multiquantal release was required to activate NMDA receptors at mature synapses, suggesting a developmental redistribution of NMDA receptors. These changes in the synaptic conductance waveform result in a faster rising EPSP and reduced spike latency in mature granule cells. Mature granule cells also have a significantly decreased input resistance, contributing to a faster decaying EPSP and a reduced spike jitter. We suggest that these concurrent developmental changes, which increase the temporal precision of EPSP-spike coupling, will increase the fidelity with which sensory information is processed within the input layer of the cerebellar cortex.

Key words: cerebellum; granule cell; EPSC; AMPA receptor; NMDA receptor; postnatal development; intrinsic membrane properties; EPSP

\section{Introduction}

Excitatory synaptic transmission in the CNS is mediated primarily by AMPA and NMDA receptors (AMPARs and NMDARs). The two glutamate receptor subtypes differ in their gating properties, kinetic behavior, and ion permeabilities (Edmonds et al., 1995). Although both receptor types often occur within individual synaptic densities (Kharazia et al., 1996; Takumi et al., 1999; Racca et al., 2000) and can be coactivated by single transmitter quanta (Bekkers and Stevens, 1989; Jones and Baughman, 1991; Silver et al., 1992; Umemiya et al., 1999), their relative number and spatial distribution vary between synapses (Takumi et al., 1999; Racca et al., 2000). Certain synapses initially express NMDARs exclusively, and only later acquire AMPARs (Isaac et al., 1995; Liao et al., 1995; Petralia et al., 1999). Subsequently, the relative numbers of the two receptors can vary in response to both short- and long-term changes in synaptic activity (Shi et al., 1999; Futai et al., 2001; Takahashi et al., 2003). For a given synaptic glutamate transient, the precise repertoire of receptors and their

\footnotetext{
Received March 20, 2003; revised April 30, 2003; accepted May 5, 2003.

This work was supported by a Wellcome Trust Programme Grant (S.C.-C.), a Wellcome Trust Traveling Fellowship (L.C.), and a Wellcome Trust Collaborative Research Initiative Grant (M.F. and Z. Nussar). S.C.-C. is a Royal SocietyWolfson Research Merit Award holder. We are indebted to David DiGregorio for help and advice during the course of this work. We thank Giampaolo D'Alessandro, Robert Cannon, Jason Rothman, and Stephen Traynelis for provision of software; Lorna Medhurst and Ranji Samarasinghe for technical assistance; and Beverley Clark, Michael Häusser Pablo Monsivais, Zoltan Nusser, Angus Silver, and Tomoyuki Takahashi for comments on this manuscript.

Correspondence should be addressed to either of the following: Mark Farrant, Department of Pharmacology, University College London, Gower Street, London WC1E 6BT, UK, E-mail: m.farrant@ucl.ac.uk; or Stuart Cull-Candy, Department of Pharmacology, University College London, Gower Street, London WC1E 6BT, UK, E-mail s.cullcandy@ucl.ac.uk.

Copyright $\odot 2003$ Society for Neuroscience $\quad$ 0270-6474/03/236074-12\$15.00/0
}

subcellular location will determine the size and duration of the synaptic conductance. This, together with the electrotonic location of the synapse and the integrative properties of the cell, governs the properties of the somatic EPSP (Rall, 1967; Jack and Redman, 1971). In turn, the size and shape of the EPSP dictate not only how many synaptic inputs are required to reach spike threshold and the time period within which summation takes place, but also the temporal precision of spike generation (Fricker and Miles, 2000; Galarreta and Hestrin, 2001) and the efficacy of information transfer (London et al., 2002). During neuronal development, factors that determine the postsynaptic conductance and the cell membrane properties are known to change (McCormick and Prince, 1987; Futai et al., 2001; Taschenberger et al., 2002). Dissecting the relative role of these factors in shaping the EPSP is important to our understanding of how synaptic integration is altered during development (Brenowitz and Trussell, 2001; Kuba et al., 2002).

Cerebellar granule cells (GCs) form the input layer of the cerebellar cortex (Palay and Chan-Palay, 1974) and integrate sensory information carried by mossy fibers (MFs) to produce parallel fiber signals that influence the activity of inhibitory interneurons and Purkinje cells (for review, see De Schutter and Bjaalie, 2001). Mutations or manipulations that disrupt integration at this synapse generate motor abnormalities (Kadotani et al., 1996; Watanabe et al., 1998; Hashimoto et al., 1999), suggesting that maturation of the MF-GC synapse is critical in the development of mature motor behavior. Transmission at the MF-GC synapse is mediated by glutamate acting on AMPARs and NMDARs (Silver et al., 1992). During cerebellar development, changes in AMPAR (Baude et al., 1994; Mosbacher et al., 1994; Ripellino 
et al., 1998) and NMDAR (Akazawa et al., 1994; Monyer et al., 1994) subunit expression are believed to underlie changes in the properties of the receptors (Farrant et al., 1994; Takahashi et al., 1996; Smith et al., 2000) and of the synaptic currents (Takahashi et al., 1996; Rumbaugh and Vicini, 1999; Cathala et al., 2000; Wall et al., 2002). Despite this wealth of knowledge, it is not known how, or indeed whether, these changes influence synaptic integration at the MF-GC synapse.

We recorded from immature GCs with newly formed MF synapses and from mature GCs. At both ages the electrotonically compact nature of the cells enabled us to record EPSCs with high temporal resolution. At immature synapses, both AMPARs and NMDARs contribute to quantal and action potential-evoked currents. At mature synapses, quantal EPSCs are mediated solely by AMPARs, and NMDAR activation occurs only after multiquantal release, indicating spatial segregation of the two receptor types. At mature synapses there is a marked speeding of the AMPARmediated component of the quantal EPSC that is reflected in the properties of the evoked current. Using both dynamic currentclamp and passive neuronal models, we show how these developmental changes in conductance waveform and concurrent changes in membrane properties combine to generate a briefer EPSP and enhance the temporal precision of spike generation.

\section{Materials and Methods}

Slice preparation and recording. Parasagittal slices $(200-250 \mu \mathrm{m})$ were cut from the cerebellar vermis of C57BL/6J mice aged between postnatal day (P) 7 and P52, as described previously (Cathala et al., 2000). The "slicing" solution contained (in mM): $125 \mathrm{NaCl}, 2.5 \mathrm{KCl}, 1 \mathrm{CaCl}_{2}, 2 \mathrm{MgCl}_{2}, 26$ $\mathrm{NaHCO}_{3}, \quad 1.25 \mathrm{NaH}_{2} \mathrm{PO}_{4}, 25$ glucose; 0.02-0.08 D-2-amino-5phosphonopentanoic acid (D-AP5), pH 7.4, when bubbled with 95\% $\mathrm{O}_{2}$ and $5 \% \mathrm{CO}_{2}$. Patch-clamp recordings were made at physiological temperature $\left(35-38^{\circ} \mathrm{C}\right)$ with Axopatch-200A or $-200 \mathrm{~B}$ amplifiers (Axon Instruments, Union City, CA). The "external" solution differed from the slicing solution in containing $2 \mathrm{mM} \mathrm{Ca}^{2+}$ and $1 \mathrm{mM} \mathrm{Mg}^{2+}$. Patch pipettes were made from thick-walled borosilicate glass tubing and fire polished to a resistance of 10-12 $\mathrm{M} \Omega$. Capacitance measures were determined directly from the amplifier settings; no series resistance compensation was used. The "internal" solution contained (in mM): $130 \mathrm{~K}$-gluconate, $10 \mathrm{HEPES}, 5$ EGTA, $4 \mathrm{NaCl}, 1 \mathrm{CaCl}_{2}, 2 \mathrm{Mg}$-ATP (adjusted to $\mathrm{pH} 7.3$ with $\mathrm{KOH})$. All voltage records were corrected for a measured liquid junction potential of $4.8 \mathrm{mV}$.

Stimulation. Individual MF axons were stimulated using patch pipettes filled with extracellular solution placed in the granule cell layer. Stimuli (10-50 $\mu$ sec duration) were delivered using a constant voltage stimulus isolator (Digitimer DS2, Welwyn Garden City, UK). A single fiber was identified using minimal stimulation, such that increasing the stimulus voltage triggered an all-or-none response that did not increase in amplitude with further increases in intensity (Silver et al., 1996). The stimulation voltage was set $5 \mathrm{~V}$ above threshold to ensure reliable fiber stimulation.

Data analysis. Signals were recorded on digital audiotape (DTR-1204, BioLogic, Claix, France; DC to $20 \mathrm{kHz}$ ). Spontaneous and evoked EPSCs were filtered at $5 \mathrm{kHz}(-3 \mathrm{~dB}$; eight-pole low-pass Bessel filter) and digitized at $33 \mathrm{kHz}$ (Digidata 1200; Axotape, Axon Instruments). Spontaneous EPSCs were detected with a scaled template detection method using Axograph 4.6 (Axon Instruments). The percentage coefficient of variation (c.v.) of the spontaneous EPSC amplitudes was calculated as:

$$
\text { c.v. }=\left(\frac{\sqrt{\text { peak variance }- \text { noise variance }}}{\text { mean }}\right) \times 100 .
$$

The noise variance was determined from the SD of concatenated $1 \mathrm{msec}$ epochs immediately preceding each detected event. At all ages, EPSC decays were best described by the sum of two exponential functions:

$$
A(t)=A_{\text {fast }}\left(\exp \left(-t / \tau_{\text {fast }}\right)+A_{\text {slow }}\left(\exp \left(-t / \tau_{\text {slow }}\right),\right.\right.
$$

where $\tau_{\text {slow }}$ and $\tau_{\text {fast }}$ are the decay time constants of the slow and fast component and $A_{\text {slow }}$ and $A_{\text {fast }}$ are their respective amplitudes. The weighted time constant of decay $\left(\tau_{\text {decay }}\right)$ was calculated from the integral of the current, independently of fitting, according to:

$$
\tau_{\text {decay }}=\frac{\int_{t_{\text {peak }}}^{t_{\infty}} I(t) d t}{I_{\text {peak }}},
$$

where $t_{\text {peak }}$ is the time of the EPSC peak, $t_{\infty}$ is the time at which the current had returned to the pre-event baseline, and $I_{\text {peak }}$ the peak amplitude of the EPSC.

Voltage recordings were filtered at $2 \mathrm{kHz}$ and digitized at $10 \mathrm{kHz}$, except for EPSPs evoked by conductance injection, which were filtered at $5 \mathrm{kHz}$ and digitized at $40 \mathrm{kHz}$. Waveforms were analyzed using IGOR Pro 4.04 (Wavemetrics, Lake Oswego, OR), Axograph 4.6, or pCLAMP 8 (Axon Instruments). Spike threshold was estimated either visually or as the inflection point of the first derivative of the waveform; the results from the two methods differed by $<1 \mathrm{mV}$. Spike latency was measured as the time between EPSP onset and spike peak.

Conductance injection. Cells were stimulated, in the absence of any receptor antagonists, using the conductance injection technique (Robinson and Kawai, 1993). The opening of synaptic AMPAR channels was modeled by a conductance $g_{\mathrm{AMPA}}(t)$, causing a current $I_{\mathrm{AMPA}}(t)$ that depended on the membrane potential $V(t)$ :

$$
I_{\mathrm{AMPA}}(t)=g_{\mathrm{AMPA}}(t)\left[V(t)-E_{\mathrm{rev}}\right],
$$

where $E_{\text {rev }}$ is the reversal potential of the conductance. The opening of synaptic NMDAR channels was modeled with an additional Boltzmann nonlinearity:

$$
I_{\mathrm{NMDA}}(t)=\frac{g_{\mathrm{NMDA}}(t)\left[V(t)-E_{\mathrm{rev}}\right]}{1+K_{1} \exp \left(-K_{2} V(t)\right)}
$$

where $K_{1}(0.32)$ and $K_{2}(0.06)$ are the parameters that determine the voltage dependence of $\mathrm{Mg}^{2+}$ block (Harsch and Robinson, 2000). These parameters adequately replicated the behavior of NMDAR-mediated quantal EPSCs recorded at $-60,-25$, and $+40 \mathrm{mV}$ in immature GCs. An analog circuit (SM-1 conductance injection amplifier; Cambridge Conductance, Cambridge, UK) was used to produce the current command signal from the instantaneous membrane potential signal and a computer-generated conductance command waveform. The conductance command AMPAR waveforms ( $g_{\text {syn }} 8 \mathrm{~A}$ and $\left.g_{\text {syn }} 39\right)$ were based on the population averages of quantal EPSCs obtained at the two ages (P8 and P39) in the presence of D-AP5 and 7-chlorokynurenic acid (7-CK) (averages of normalized waveforms). In some cases, when stimulating quantal EPSPs attributable to both AMPARs and NMDARs, we used a combined AMPAR + NMDAR waveform based on the EPSC recorded at rest in the presence of $\mathrm{Mg}^{2+}\left(g_{\text {syn }} 8\right)$ and assumed a negligible change in the current through NMDARs attributable to voltagedependent changes in $\mathrm{Mg}^{2+}$ block (EPSP peak $<5 \mathrm{mV}$ ). Similar results were obtained when the opening of synaptic NMDAR channels was modeled separately using the Boltzmann nonlinearity. To enable the injection of noise-free command waveforms (and to allow subsequent use in neuronal models; see below), the population EPSC averages were fit either in NEURON 5.1 (Hines and Carnevale, 1997) (http://www.neuron.yale.edu) or IGOR Pro by functions having an exponential rise and either a double or triple exponential decay. For use in dynamic clamp recordings, the fitted functions were scaled to the desired peak conductance, and individual command waveforms were generated (IGOR Pro) for injection using pCLAMP 8 (Axon Instruments).

Neurobiotin filling and neuronal reconstruction. Neurobiotin (Vector Laboratories, Burlingame, CA) was added to the internal solution $(5 \mathrm{mg} / \mathrm{ml})$, and cells were loaded in the whole-cell configuration. After overnight storage in cold 0.1 m PBS (Sigma, St. Louis, MO) containing 3\% paraformaldehyde, slices were washed in PBS and incubated in Triton X-100 (4\%) containing 30 $\mathrm{mg} / \mathrm{ml}$ fluorescein streptavidin (Vector Laboratories). The slices were mounted in VectaShield medium (Vector Laboratories) and viewed under a 
confocal microscope (Leica TCS SP, Leica Microsystems, Milton Keynes, UK). For reconstruction of representative granule cells, stacks of confocal images were viewed with ImageJ 1.25 (http://rsb.info.nih.gov/ij/), and measurements were made using the Neuron Morpho plugin (Giampaolo D’Alessandro; http://www.maths.soton.ac.uk/staff/D’Alessandro/research/ morpho/). For each measured section, the $x, y$, and $z$ coordinates and section radius were recorded. No correction was made for tissue shrinkage.

Passive neuronal simulations. Modeling was performed using NEURON 5.1 or 5.3. Neuronal reconstructions were converted to NEURON format using the neuron morphology viewer Cvapp (Robert Cannon; http://www.compneuro.org). Specific membrane capacitance $\left(C_{\mathrm{m}}\right)$, specific membrane resistance $\left(R_{\mathrm{m}}\right)$, and intracellular resistivity $\left(R_{\mathrm{i}}\right)$ were assumed to be uniform across each cell. $C_{\mathrm{m}}$ was set at $0.9 \mu \mathrm{F} / \mathrm{cm}^{2}$ (Gentet et al., 2000), and $R_{\mathrm{i}}$ was set at $100 \Omega \mathrm{cm}$. For each simulation, a population value of $R_{\mathrm{m}}$ was used. This was calculated to match the average measured resting input resistance of the age group, according to:

$$
R_{\mathrm{m}}=\overline{R_{\mathrm{in}}}\left(\overline{C_{\mathrm{in}}} / C_{\mathrm{m}}\right),
$$

where $\overline{R_{\text {in }}}$ and $\overline{C_{\text {in }}}$ are the average values of input resistance and capacitance, respectively $\left(\mathrm{P} 8,9.19 \mathrm{k} \Omega \cdot \mathrm{cm}^{2} ; \mathrm{P} 39,2.55 \mathrm{k} \Omega \cdot \mathrm{cm}^{2}\right.$; in both cases the membrane conductance of the axon was set to zero). The surface areas of the reconstructed neurons (soma and dendritic compartments) predicted $C_{\text {in }}$ values of $5.3 \mathrm{pF}$ at P8 and $2.9 \mathrm{pF}$ at P39 (both within the range of experimentally observed values). The EPSC waveforms used to generate the conductance command waveforms were first corrected for cell-electrode filtering (Channel Lab; Synaptosft, Decatur, GA). In addition to models based on reconstructed neuronal morphologies, simplified single-compartment models were used to assess the effects of synaptic and intrinsic membrane parameters on the EPSP generated in response to either quantal or evoked conductance waveforms. In this case, for simulation at different voltages, the value of $R_{\text {in }}$ was adjusted according to the measured subthreshold current-voltage relationships at each age (see Fig. 4). The integration time step for all simulations was $25 \mu$ sec.

Average data are expressed as mean \pm SEM. When data were distributed normally (Shapiro-Wilk test), statistical differences between groups were tested using the two-tailed Student's $t$ test and considered significant at $p<0.05$ (STATISTICA 5.1; StatSoft, Tulsa, OK). Other tests (Mann-Whitney $U$, Kolmogorov-Smirnov, Spearmann rank order correlation) were used as indicated.

\section{Results}

\section{Spontaneous EPSCs in immature and mature GCs are quantal events}

To quantify the developmental change in synaptic conductance waveform between immature and mature MF-GC synapses, we made recordings at physiological temperature $\left(\sim 37^{\circ} \mathrm{C}\right)$ in acute slices of cerebellum from mice in two age ranges. Immature GCs were examined between P7 and P9 ( $8.2 \pm 0.1 ; n=72$ cells; "P8"), and mature GCs were examined between P34 and P52 (39.1 \pm $0.3 ; n=96$; "P39").

In the presence of the selective $\mathrm{GABA}_{\mathrm{A}} \mathrm{R}$ antagonist 2-(3-carboxypropyl)-3-amino-6-(4-methoxyphenyl)pyridazinium bromide (10 $\mu \mathrm{M}$; SR-95531) and the NMDAR antagonists AP5 $(20 \mu \mathrm{M})$ and $7-\mathrm{CK}(20 \mu \mathrm{M})$, spontaneous synaptic currents were detected that were fully blocked by the non-NMDAR antagonist 6-cyano-7-nitroquinoxaline-2,3-dione $(5 \mu \mathrm{M})$ or the selective AMPAR antagonist GYKI 53655 (100 $\mu$; data not shown). These AMPAR-mediated EPSCs occurred with a similar frequency at both ages and had similar mean peak amplitudes (Table 1). Consistent with all events being quantal in nature, blockade of action potentials with tetrodotoxin (TTX; $0.5 \mu \mathrm{M}$ ) affected neither the amplitude nor the frequency of the currents (Fig. $1 A-C$ ). The c.v. of the peak amplitudes was $43.5 \pm 2.0 \%$ at $\mathrm{P} 8$ and $40.5 \pm 3.1 \%$ at P39. In contrast with miniature EPSCs in GCs from mature rats (Wall and Usowicz, 1998; Wall et al., 2002), all amplitude histograms, although skewed
Table 1. Properties of quantal EPSCs in immature and mature GCs

\begin{tabular}{lcc}
\hline & Immature (P8) & Mature (P39) \\
\hline Frequency (Hz) & $0.6 \pm 0.2$ & $1.0 \pm 0.4$ \\
AMPAR-mediated component $(-70 \mathrm{mV})$ & & \\
$\quad$ Amplitude $(\mathrm{pA})$ & $21.7 \pm 2.3$ & $19.7 \pm 1.0$ \\
$10-90 \%$ rise time (msec) & $0.20 \pm 0.01$ & $0.15 \pm 0.01^{*}$ \\
$\tau_{\text {decay }}$ (msec) & $1.47 \pm 0.17$ & $0.79 \pm 0.06^{*}$ \\
$\tau_{\text {fast }}$ (msec) & $0.66 \pm 0.05$ & $0.43 \pm 0.04^{*}$ \\
$\tau_{\text {slow }}$ (msec) & $6.91 \pm 1.71$ & $4.38 \pm 1.02$ \\
$A_{\text {fast }}(\%)$ & $88.9 \pm 1.8$ & $91.4 \pm 1.3$ \\
Charge transfer (fC) & $34.8 \pm 3.5$ & $19.2 \pm 2.3^{*}$ \\
NMDAR-mediated component $(-25 \mathrm{mV})$ & & \\
Amplitude (pA) & $3.1 \pm 0.6$ & - \\
$10-90 \%$ rise time (msec) & $0.86 \pm 0.29$ & - \\
$\tau_{\text {decay }}$ (msec) & $18.2 \pm 8.1$ & - \\
Charge transfer (fC) & $61.4 \pm 18.8$ & - \\
\hline
\end{tabular}

Measurements are from 10 cells at each age (except for NMDA data, where $n=5$ ). ${ }^{*}$ Significant differences $(p<$ 0.05 ). Horizontal bars indicate absence of NMDAR-mediated component in mature GCs.

toward larger amplitudes, lacked multiple discrete peaks (Fig. $1 B, D, E)$. Moreover, we found no evidence of inflections in their rising-phase large events, and there was no positive correlation between their amplitude and their rise time (Fig. 1D,E) (cf. Wall and Usowicz, 1998) or their width (data not shown). Thus, at both immature and mature synapses, spontaneous EPSCs exhibit properties of individual quantal events, with a high amplitude variance.

\section{AMPAR-mediated quantal EPSCs become faster during development}

The decay of the AMPAR-mediated quantal EPSCs was best described by a double exponential (Fig. 2A), with parameters at P8 broadly similar to those reported for spontaneous EPSCs recorded from GCs of immature rats (Silver et al., 1996; Wall et al., 2002). In mature GCs, the rise and decay of the EPSCs were significantly faster (Table 1 ). The reduction in rise time did not simply reflect altered RC filtering by the electrode-cell circuit, because the mean corner frequency was not different at the two ages $(1.35 \pm 0.07 \mathrm{kHz}$ at $\mathrm{P} 8$ and $1.47 \pm 0.12 \mathrm{kHz}$ at $\mathrm{P} 39 ; p>$ $0.05)$. The speeding of the decay was caused by a reduction in $\tau_{\text {fast }}$ with no significant change in its relative amplitude or in the value of $\tau_{\text {slow }}$ (Table 1, Fig. $2 B$ ). Overall, these kinetic changes resulted in an approximate halving of the charge transfer during the AMPAR-quantal EPSC (Fig. 2C).

\section{NMDA receptors do not contribute to quantal EPSCs in mature GCs}

To investigate the contribution of NMDARs to quantal EPSCs, we made recordings in the presence or absence of NMDAR antagonists. To determine the activation of NMDARs under physiological conditions, we included $1 \mathrm{mM} \mathrm{Mg}^{2+}$ in the external solution and recorded currents at two holding potentials: the first near rest ( -60 and $-80 \mathrm{mV}$ for $\mathrm{P} 8$ and $\mathrm{P} 39$, respectively) and the second near action potential threshold $(-25$ and $-35 \mathrm{mV}$, respectively) (see Fig. 4), where we would expect partial relief of $\mathrm{Mg}^{2+}$ block. In P8 GCs, blockade of NMDARs accelerated the decay of quantal EPSCs at both membrane potentials (Fig. $3 A, C)$. The decay time $\left(\tau_{\text {decay }}\right)$ was reduced from $3.0 \pm 0.5$ to $1.6 \pm 0.2 \mathrm{msec}$ at $-60 \mathrm{mV}$, and from $7.1 \pm 1.4$ to $1.9 \pm 0.4 \mathrm{msec}$ at $-25 \mathrm{mV}(n=5)$. Subtracting the current recorded in AP5 from that recorded in control conditions revealed the NMDARmediated component. At $-25 \mathrm{mV}$, the amplitude of this component was $25.2 \%$ of the dual-component quantal EPSC (Table 1). As expected, given the voltage-dependent blocking action of 


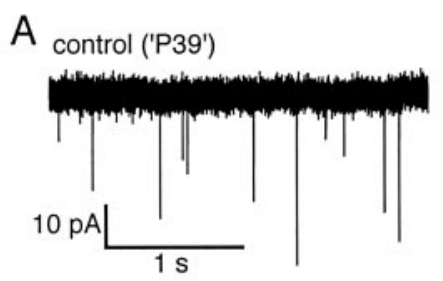

B

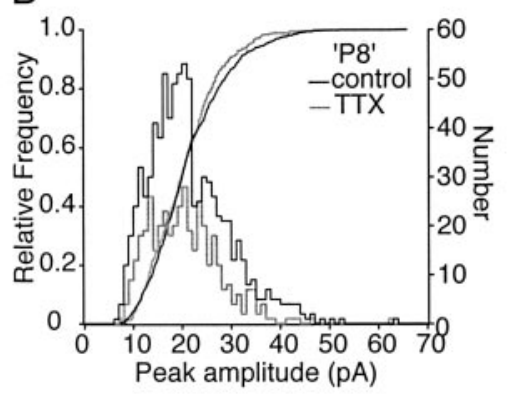

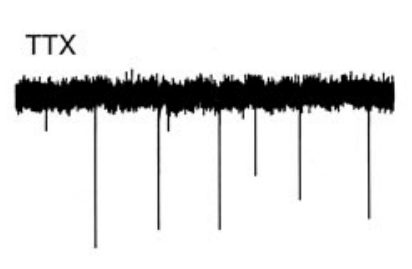

$\mathrm{C}$

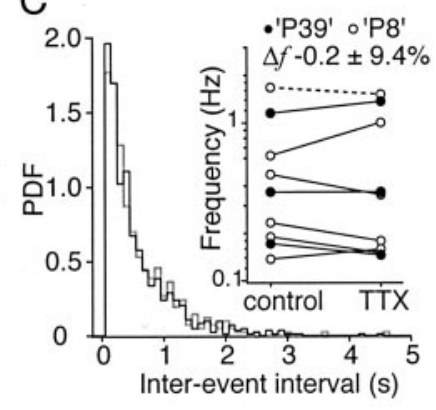

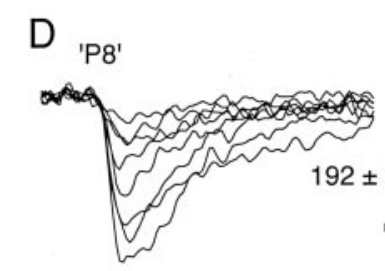

$10 \mathrm{pA}$

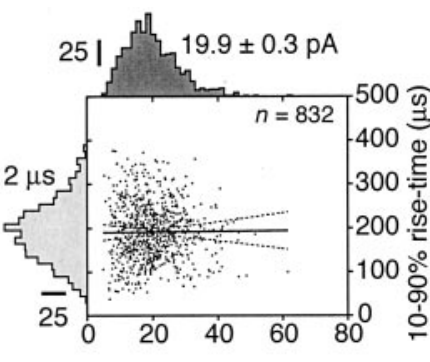

E 'P39'

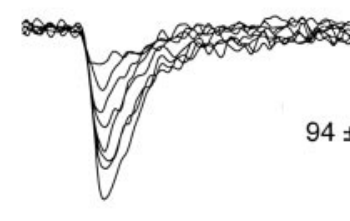

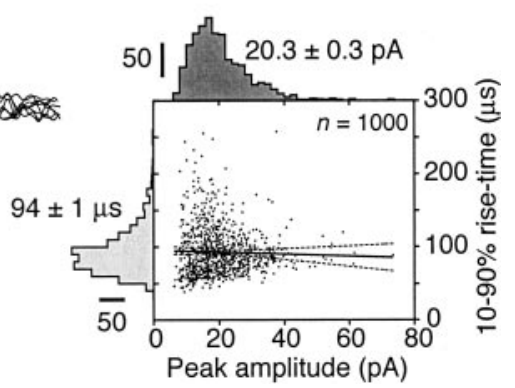

Figure 1. Properties of spontaneous EPSCs in mature and immature GCS. A, Continuous records showing spontaneous EPSCs recorded from a 'P39' GC (P35) in the absence and presence of TTX $\left(V_{\mathrm{m}}=-70 \mathrm{mV}\right) . B$, Amplitude distributions of events from a 'P8' GC (P7) recorded in the absence and presence of TTX. Superimposed lines show cumulative amplitude histograms ( $p>0.05$; Kolmogorov-Smirnov test). C, Interevent interval histograms from the same cell as $B$, showing the exponential distribution of interevent intervals and the lack of effect of TTX. Inset, Summary of results from both age groups. Dotted line indicates cell shown in $C\left(\Delta f\right.$ denotes mean change in frequency across all cells). D, Superimposed spontaneous EPSCs from a P7 GC $\left(V_{\mathrm{m}}=-70 \mathrm{mV}\right)$. Right-hand panel shows a plot of peak amplitude against $10-90 \%$ rise time for the same cell, with superimposed distributions. $E$, Corresponding data for a P36 GC. In both $D$ and $E$ there is no correlation between peak and $10-90 \%$ rise time ( $p>0.05$; Spearmann rank order correlation). The solid lines show the fitted linear regressions, and the dotted lines show the $95 \%$ confidence limits.

A

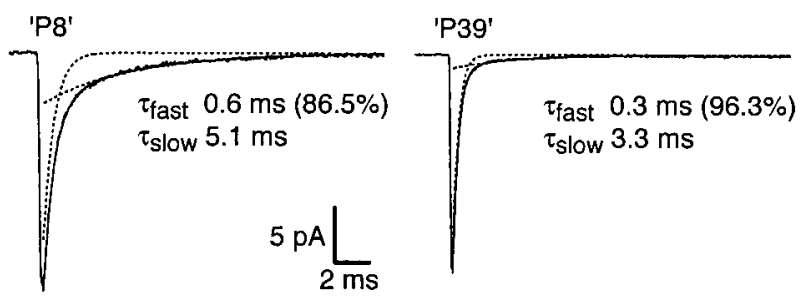

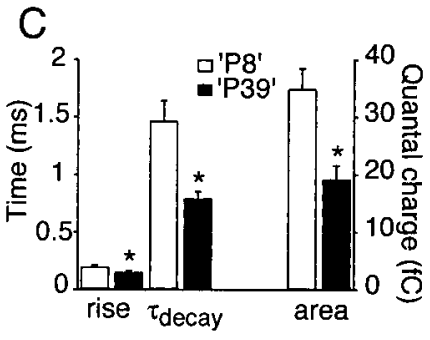

Figure 2. Speeding of the AMPAR-mediated quantal EPSC. A, Representative averaged AMPAR - quantal EPSCs at $-70 \mathrm{mV}$, from 'P8' and 'P39' GCS (P8 and P36). At both ages, the decay phase was best fitted by a double exponential function (solid line). The individual components of the fit are shown as dotted lines. $B$, For each age group the mean decay time constants $\left(\tau_{\text {fast }}\right.$ and $\left.\tau_{\text {slow }}\right)$ are plotted against their relative contributions to the EPSC amplitudes. Error bars indicate SEM. At P8, $\tau_{\text {fast }}=0.66 \pm 0.05 \mathrm{msec}(88.9 \pm 1.8 \%)$ and $\tau_{\text {slow }}=$ $6.91 \pm 1.71 \mathrm{msec} ;$ at P39, $\tau_{\text {fast }}=0.59 \pm 0.04 \mathrm{msec}(91.4 \pm 1.3 \%)$ and $\tau_{\text {slow }}=4.38 \pm 1.02$ msec. Asterisk indicates significant difference between $\tau_{\text {fast }}$ values (Mann-Whitney $U$ test). C, Histogram of spontaneous EPSC $10-90 \%$ rise, $\tau_{\text {decay }}$, and quantal charge in both age groups. Asterisks indicate significant difference between groups (rise and $\tau_{\text {decay }}, t$ test; quantal charge, Mann-Whitney $U$ test).

$\mathrm{Mg}^{2+}$, the contribution of NMDARs to the peak of the quantal EPSCs was reduced at $-60 \mathrm{mV}$ to $9.5 \%$ (Fig. $3 A$ ). In marked contrast, blockade of NMDARs in P39 GCs had no effect on the decay of quantal EPSCs, either at rest or near action potential threshold (Fig. $3 B, C$ ). The absence of an NMDAR-mediated component to the quantal current was confirmed in additional recordings, made under conditions designed to maximize the likelihood of detecting any NMDAR activation $(+40 \mathrm{mV}$, with added glycine increased from 3 to $10 \mu \mathrm{M}$; data not shown; $n=5$ ). These results indicate that in adult GCs, NMDARs are not activated during quantal events.

\section{GC intrinsic membrane properties change during development}

Changes in the kinetics of the quantal EPSC occur against a background of developmental changes in GC intrinsic membrane properties, and it is the interplay of these changes that will determine the developmental changes in the EPSP. Although previous studies (D’Angelo et al., 1994; Brickley et al., 1996, 2001) have identified several developmental changes in GC properties, these have generally been examined over a restricted age range and only at room temperature. To characterize intrinsic membrane properties at physiological temperature, we examined the response of immature and mature GCs to constant current injection (Fig. $4 A)$. P8 GCs had an input capacitance $\left(C_{\text {in }}\right)$ of $3.9 \pm 0.1 \mathrm{pF}(n=$ $59)$, an input conductance $\left(G_{\text {in }}\right)$ of $0.73 \pm 0.1 \mathrm{nS}(n=28)$, and a resting membrane potential $\left(V_{\mathrm{m}}\right)$ of $-58.8 \pm 1.5 \mathrm{mV}(n=51)$. P39 GCs were smaller $\left(C_{i n} 3.0 \pm 0.1 \mathrm{pF} ; n=96\right)$, had a higher input conductance $\left(G_{\text {in }} 1.48 \pm 0.10 \mathrm{nS} ; n=37\right)$, and were more hyperpolarized $\left(V_{\mathrm{m}}-78.6 \pm 0.5 \mathrm{mV} ; n=84\right.$; all $\left.p<0.05\right)$. In agreement with previous studies, mature GCs had action potentials that were brief, and all cells supported high-frequency firing in response to sustained depolarization (D’Angelo et al., 1995; Brickley et al., 1996), whereas P8 GCs fired broad action potentials that tended to accommodate at high stimulus intensities (data not shown). The subthreshold current-voltage relationship of P8 GCs was linear, whereas P39 GCs exhibited both inward and outward rectification (Fig. $4 B, C$ ). The spike threshold potential also decreased during development, by $\sim 8.5 \mathrm{mV}$ ( $p<0.05$; Mann-Whit- 
A

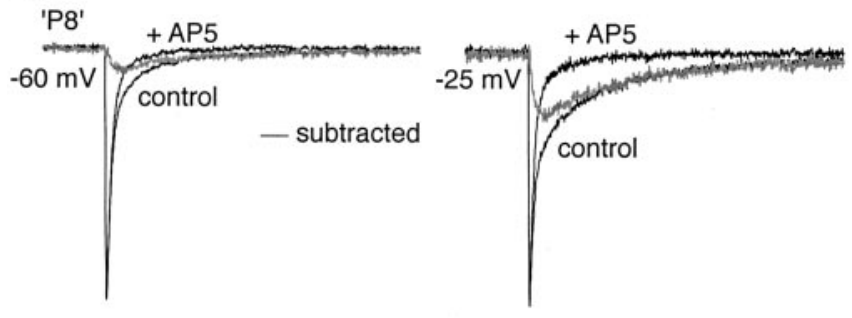

B

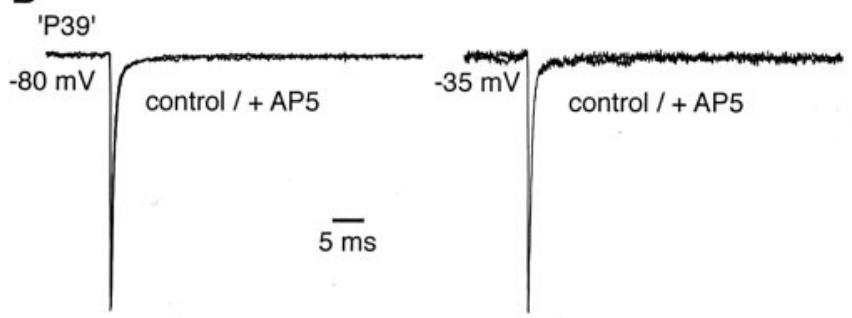

C

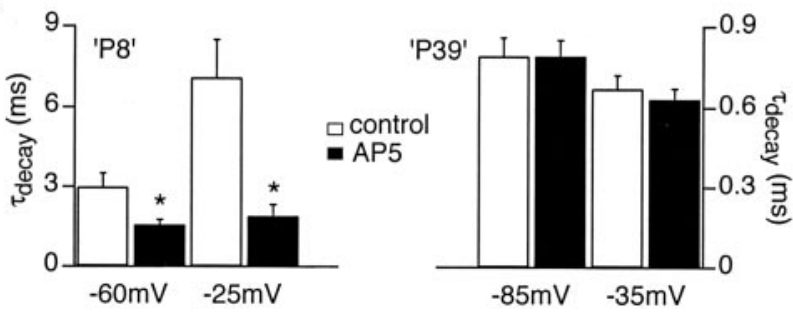

Figure 3. Developmental change in NMDAR contribution to quantal EPSCs. A, Scaled population average EPSCs recorded from $\mathrm{P} 8 \mathrm{GCS}(n=5)$. Recordings were made at two potentials: resting potential $(-60 \mathrm{mV})$ and action potential threshold $(-25 \mathrm{mV})$ (Fig. 4). B, Population average EPSCs from P39 GCs at the corresponding potentials ( $n=9$ at $-80 \mathrm{mV}$ and $n=7$ at $-35 \mathrm{mV}$ ). Calibration applies to both $A$ and $B$. The term + AP5 denotes addition of both AP5 and 7-CK. C, Histogram showing the effect of NMDAR blockade on the $\tau_{\text {decay }}$ of the EPSCs. Note the significant effect in immature $\mathrm{GCs}\left({ }^{*} p<0.05\right)$ and the lack of effect in mature $\mathrm{GCs}$ (note also the 10 -fold change in scale on the ordinate).

ney $U$ test) (Fig. $4 D$ ). The emergence of the mature phenotype was reflected in a nearly three-fold increase in the current required to reach spike threshold $(p<0.05)$ (Fig. $4 E)$.

\section{Somatic conductance injection effectively mimics a dendritic synaptic input}

To determine how the observed developmental changes in GCs interact to influence the EPSP and EPSP-spike coupling, we used the technique of dynamic current clamp (Robinson and Kawai, 1993). Using a conductance command waveform to evoke EPSPs, rather than recording spontaneous events, obviated the need for pharmacological intervention (which may alter intrinsic membrane properties) (Brickley et al., 1996; Hausser and Clark, 1997) and allowed manipulation of the conductance waveform in a single cell.

For many neurons, the location of a synaptic conductance within the dendritic tree profoundly influences the amplitude and time course of the resulting somatic EPSP (Rall, 1967; Reyes, 2001). In such neurons, injection of a conductance at the soma will not mimic the somatic EPSP that would result from dendritic input. GCs receive MF excitatory input at the distal end of their dendrites (Hamori and Somogyi, 1983). Although these dendrites are short, we wished to determine whether GCs at all ages behaved as single electrical compartments (Silver et al., 1992) or whether the developmental changes in their morphology
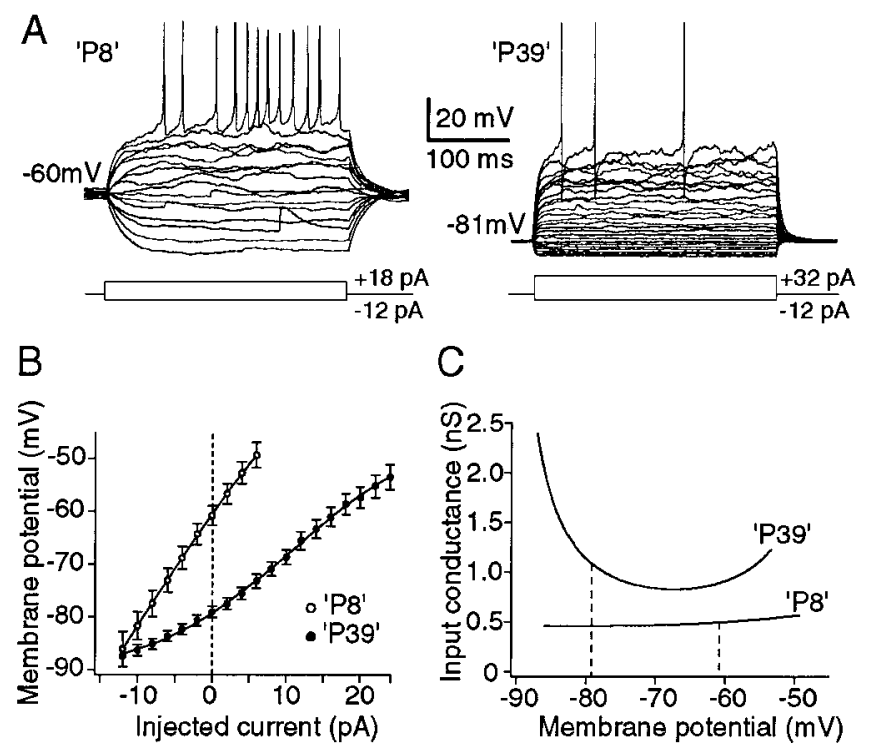

C
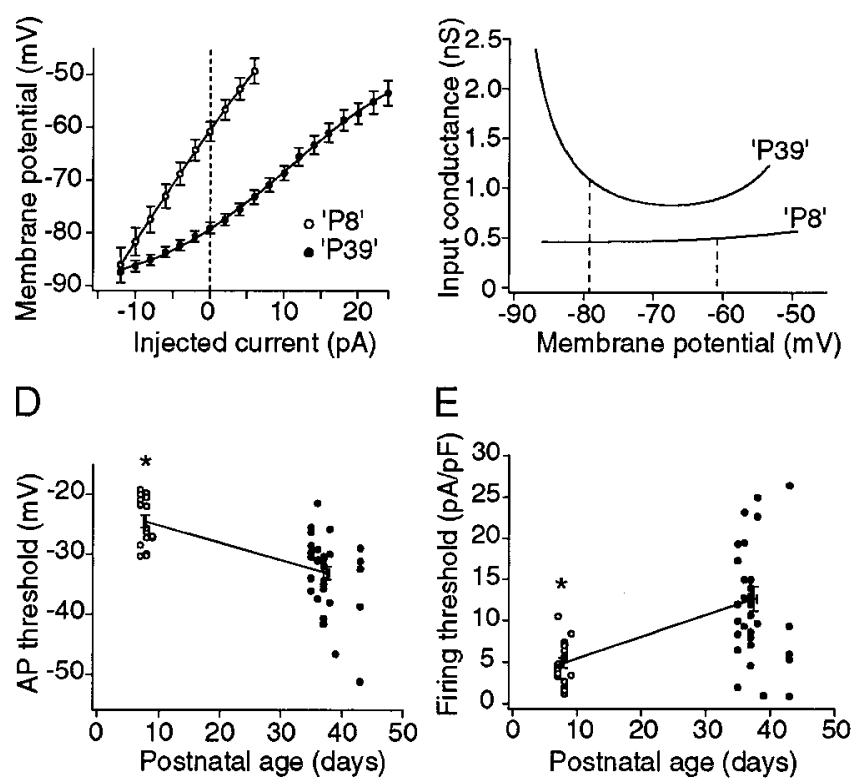

Figure 4. Intrinsic membrane properties of $\mathrm{GCS}$ change during development. $A$, Characteristic responses of immature ('P8') and mature ('P39') GCs (P7 and P37) to constant current injection (2 pA steps). Responses shown are only those up to the first current step that induced spiking in each cell. $B$, Subthreshold current-voltage relationship for P8 $(n=25)$ and P39 $(n=$ 26) GCs. Vertical error bars indicate SEM. Solid lines are fitted sigmoidal curves. C, Relationship between membrane potential and input conductance for P8 and P39 GCs (first derivative of fitted lines shown in $B$ ). Dashed lines indicate the mean resting membrane potentials for these cells. D, Plot showing the developmental decrease in action potential threshold $(-27.1 \pm 1.4$ $\mathrm{mV}, n=17$ at P8 to $-36.5 \pm 1.0 \mathrm{mV}, n=31$ at P39; ${ }^{*} p<0.05$, Mann-Whitney U test). Line connects mean values, and horizontal and vertical error bars indicate SEM. E, Equivalent plot to $D$, showing the developmental increase in current required to evoke action potentials (4.9 \pm $0.6 \mathrm{pA} / \mathrm{pF}, n=18$ at P8vs $12.7 \pm 1.5 \mathrm{pA} / \mathrm{pF}, n=31$ atP39; ${ }^{*} p<0.05$, Mann-Whitney Utest).

(Ramon y Cajal, 1995) could also impact on the properties of the somatic EPSP. Figure $5 A$ shows confocal images of representative immature and mature GCs. P8 GCs had a soma diameter of 8.5$10.5 \mu \mathrm{m}(9.5 \pm 0.5 \mu \mathrm{m} ; n=5)$ with $10-20$ neurites $(13.4 \pm 1.8)$ and a single axon extending into the molecular layer. P39 GCs had a smaller soma $(6.3-8.9 \mu \mathrm{m} ; 7.4 \pm 0.5 \mu \mathrm{m} ; n=5 ; p<0.05)$ and only four to five dendrites $(4.2 \pm 0.2)$. These dendrites often terminated in claw-like structures, formed by dendritic digits. These claws wrap around the MF terminal to generate the cerebellar glomerulus characteristic of mature MF-GC synapses (Hamori and Somogyi, 1983).

We reconstructed the GCs shown in Figure 5A, incorporated them into passive simulations within NEURON, and injected into each cell conductance waveforms based on the filtercorrected population average P8 and P39 AMPAR-quantal EPSCs (see Materials and Methods) (Fig. 5C). In the P8 cell, somatic EPSPs evoked from dendritic terminals, when compared with the EPSP induced by somatic conductance injection, were filtered only modestly (Fig. 5D) (amplitude $-9.5 \%$, rise + 

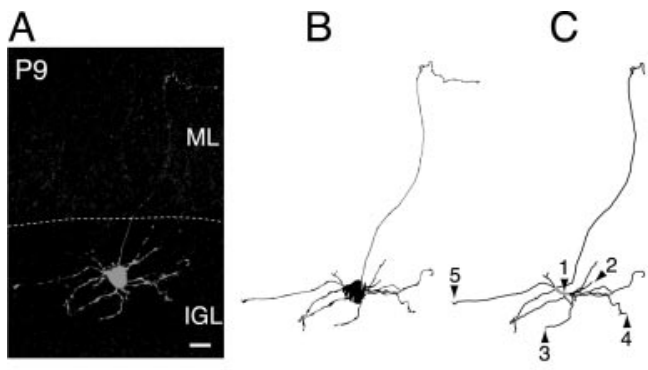

D
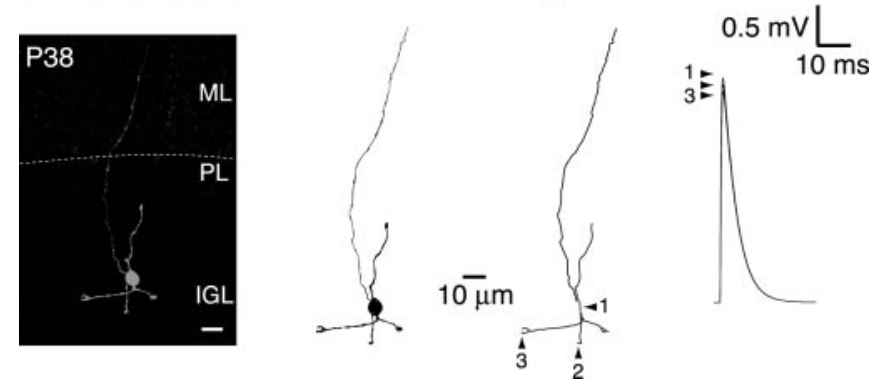

Figure 5. Effect of $\mathrm{GC}$ morphology on EPSP properties. A, Z-projections of confocal images from neurobiotin-filled P8 and P39 GCs (P9 and P38) in sagittal cerebellar slices. For the P8 GC, note the numerous dendrites and the fine axon extending into the molecular layer. For the P39 $\mathrm{GC}$, note the four dendrites, each of which terminates in dendritic digits. Scale bars, $10 \mu \mathrm{m} . \mathrm{ML}$, Molecular layer; PL, Purkinje cell layer; IGL, internal granule cell layer. B, Shape plots of the two $G C s$ reconstructed in NEURON. C, Plots showing the placement of the conductance injection in each simulation. In each case arrowhead 1 indicates the soma (gray). Calibration applies to $B$ and C.D, Somatic EPSPs recorded in response to excitation at somatic and dendritic locations, as indicated. Arrowheads (sequentially numbered according to decreasing peak amplitude; 1-5 for P9 and 1-3 for P39) indicate EPSPs originating from the corresponding sites shown in $C$.

$15.5 \%$, half-width $+2.5 \%$; mean of the most proximal and distal dendritic injections). For the P39 cell, the corresponding changes were -4.5 , +6.0 , and $+1.0 \%$. These simulations suggest that both immature and mature GCs are indeed electrically compact and approximate single electrical compartments. Accordingly, conductance injection at the soma can effectively mimic a dendritic synaptic input.

\section{AMPAR-EPSC kinetics and membrane properties differentially shape the quantal EPSP}

For conductance stimulation of real neurons we used waveforms based on the population average quantal EPSCs obtained at P8 and P39 (Fig. 6A) (see Materials and Methods). We use the terms " $g_{\text {syn }} 8$ " to denote the dual-component P8 waveform, " $g_{\text {syn }} 8 \mathrm{~A}$ " to denote the AMPAR-only P8 waveform, and " $g_{\text {syn }} 39$ " to denote the waveform from P39 GCs.

Stimulation of immature GCs with $g_{\text {syn }} 8 \mathrm{~A}$ at $-80 \mathrm{mV}$ generated quantal EPSPs that had a peak amplitude of $4.1 \pm 0.2 \mathrm{mV}$ $(n=15)$, a rise-time of $0.9 \pm 0.1 \mathrm{msec}$, and a half-width of $11.3 \pm$ $1.4 \mathrm{msec}$ (Fig. 6A, left, $B$ ). In mature GCs, the EPSPs evoked by $g_{\text {syn }} 39$ were smaller and faster, with a peak amplitude of $2.7 \pm 0.1$ $\mathrm{mV}(-34 \% ; n=8)$, a $10-90 \%$ rise-time of $0.55 \pm 0.04 \mathrm{msec}$ $(-45 \%)$, and a half-width of $5.6 \pm 0.5 \mathrm{msec}(-50 \%$; all $p<0.05$ vs P8) (Fig. $6 A$, right, $B$ ). In the latter case, these parameters were not significantly different from those of spontaneous EPSPs recorded without blockade of $\mathrm{GABA}_{\mathrm{A}}$ receptors $(n=16$; data not shown), confirming the validity of the conductance stimulation approach.

To quantify the respective roles of AMPAR-quantal EPSC kinetics and membrane properties in shaping the EPSP, we next compared the effects of the two conductance waveforms injected into cells of the same age, as well as the effects of injecting a common waveform into cells of different ages (an approach used previously at glycinergic synapses) (Singer et al., 1998). As shown in Figure $6 C$, for P39 GCs, stimulation using $g_{\text {syn }} 39$ produced EPSPs that had a half-width similar to those evoked with $g_{\text {syn }} 8 \mathrm{~A}$ $(-6 \% ; n=8 ; p>0.05)$, but they were $32 \%$ smaller and rose $29 \%$ faster $(p<0.05)$. Qualitatively similar results were obtained with P8 GCs, either at their resting potential $(-60 \mathrm{mV})$ or when held at $-80 \mathrm{mV}(n=14$; data not shown). Conversely, when a common command waveform ( $\left.g_{\text {syn }} 39\right)$ was used to stimulate P8 and P39 GCs (Fig. 6D), EPSPs in the mature cells $(n=8)$ did not differ in amplitude from those in the immature cells $(n=14$; $+3 \% ; p>0.05)$ but they had a faster rise $(-23 \%)$ and decay $(-47 \%$; both $p<0.05)$. Comparable results were obtained with $g_{\text {syn }} 8 \mathrm{~A}$ (data not shown). Overall, these data illustrate how the size and shape of quantal EPSPs in GCs change with age because of alterations in both EPSC kinetics and intrinsic membrane properties. Developmental changes in the AMPAR-quantal EPSC waveform influence the peak and rise of the EPSP but not its half-width. On the other hand, the change in intrinsic membrane properties between P8 and P39 influences the rise and decay of the EPSP but not its amplitude.

\section{Loss of NMDAR-mediated component speeds the quantal EPSP in mature GCs}

We next examined the significance of the developmental loss of the NMDAR-mediated component of the quantal EPSC. When immature GCs were stimulated at their resting potential $(-62.4 \pm 0.8 \mathrm{mV})$ with the dual-component quantal EPSC waveform $\left(g_{\text {syn }} 8\right)$, the EPSP was larger $(4.5 \pm 0.6 \mathrm{mV} ;+35 \%$; $n=9)$ and slower (rise-time $2.0 \pm 0.6 \mathrm{msec} ;+107 \%$; half-width $22.8 \pm$ $3.0 \mathrm{msec} ;+86 \%$; all $p<0.05)$ than that evoked by the AMPAR conductance alone $\left(g_{\text {syn }} 8 A\right)($ Fig. $7 A)$. The developmental loss of the NMDAR-mediated component from mature synapses acts in combination with the speeding of the AMPAR conductance to cause a further reduction in amplitude and duration of the EPSP. When measured at their respective resting membrane potentials, P39 EPSPs (Fig. 6A, right panel) were smaller than P8 EPSPs resulting from dual-component currents $(-39 \%)$ (Fig. $7 A$, right panel), with a faster rise time $(-74 \%)$ and decay (half-width $-75 \%$; all $p<0.05)$. This difference could be replicated in a simplified single-compartment passive simulation (see Materials and Methods), in which we compared the EPSPs at a common potential of $-60 \mathrm{mV}$ (Fig. $7 B$ ). The model also allowed us to quantify (in a manner analogous to that shown in Fig. 6, $C$ and $D$ ) the respective roles of the change in membrane properties and the overall change in synaptic conductance. The results were qualitatively similar to those shown in Figure 6, with the exception that consideration of the dual-component waveform shows that the acceleration in the EPSC reduces not only the peak and rise of the EPSP but also its half-width (Fig. 7C,D). Overall, the developmental loss of the NMDAR-mediated component of the quantal EPSC at P39 acts in concert with the speeding AMPAR-mediated component and the change in intrinsic membrane properties to reduce the amplitude and speed the kinetics of the quantal EPSP.

\section{NMDARs contribute to evoked EPSCs in mature GCs}

To examine how the changes in quantal properties are reflected in action potential-evoked events, we used minimal extracellular stimulation in the GC layer to activate single MF inputs (Silver et al., 1996). We recorded the evoked currents (evoked EPSCs) in standard $2 \mathrm{Ca} / 1 \mathrm{Mg}$ external solution in the presence and absence of NMDAR antagonists (AP5 and 7-CK; $20 \mu \mathrm{M}$ ), and to reveal 
the full extent of any NMDAR activation, we held the cells at $+40 \mathrm{mV}$.

In agreement with our previous data from rat GCs at room temperature (Cathala et al., 2000), MF stimulation consistently activated NMDARs in both immature and mature GCs (Fig. 8A, $B$, left). The presence of an NMDAR-mediated current in the mature evoked EPSCs, albeit reduced in relative amplitude (NMDA/ AMPA ratio, $0.84 \pm 0.19$ at $\mathrm{P} 8$ vs $0.20 \pm$ 0.05 at $\mathrm{P} 39 ; p<0.05)$, contrasts markedly with the absence of this component in the quantal EPSCs (Fig. 3). This disparity reflects a genuine difference between quantal and evoked events: in all P39 GCs, quantal events recorded before or during periods of MF stimulation were mediated solely by AMPARs $(n=4$; data not shown).

In both P8 and P39 GCs, the amplitudes of the evoked EPSCs were $\sim 5$ - to 10 -fold those of the corresponding quantal EPSCs, indicating the release of multiple vesicles in response to each MF action potential, which increases the glutamate concentration beyond the synapse (DiGregorio et al., 2002). The fact that in mature GCs NMDAR activation was seen only under this condition suggests that the receptors are located outside the synapse. By contrast, in immature GCs, the presence in the quantal EPSC of an NMDARmediated component with a submillisecond rise time suggests that NMDARs are colocalized with AMPARs within the postsynaptic density at this age.
A
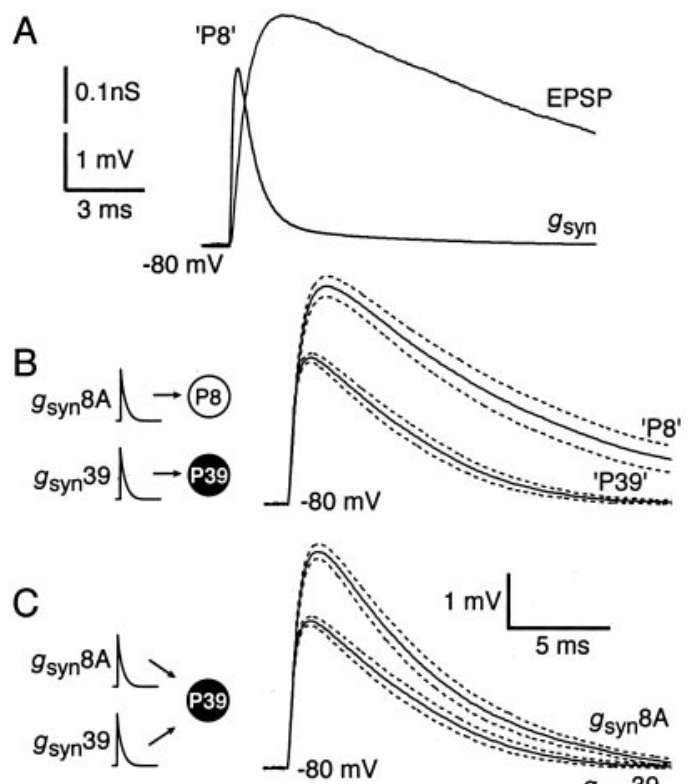

D

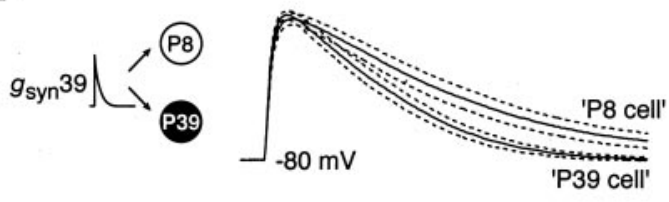

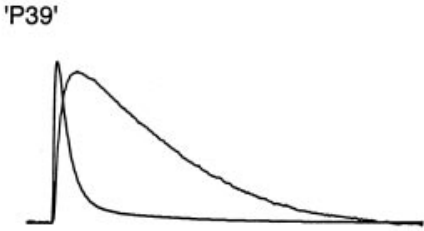
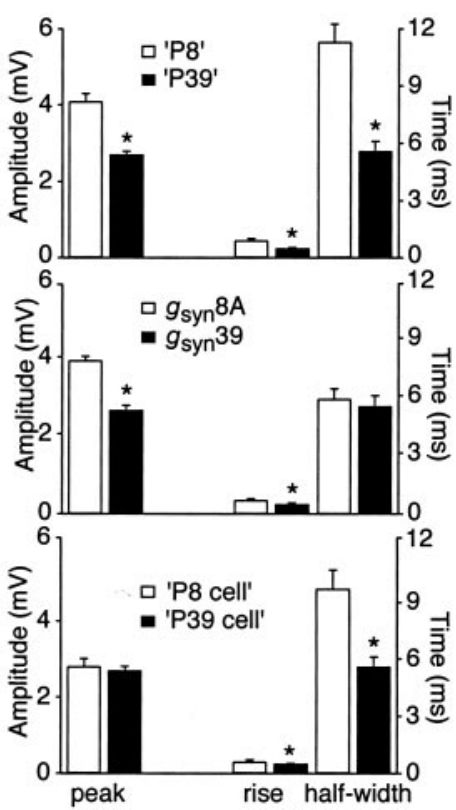

Figure 6. AMPAR-EPSPs evoked by conductance injection. A, Representative responses of 'P8' and 'P39' GCs (P7 and P37) to injection of synaptic conductance waveforms ( $g_{\text {syn }} 8 \mathrm{~A}$ and $g_{\text {syn }} 39$ ). For these cells, the P8 EPSP had a peak amplitude of $4.0 \mathrm{mV}$, a $10-90 \%$ rise-time of $0.99 \mathrm{msec}$, and half-width of $13.2 \mathrm{msec}$; the P39 EPSP had a peak amplitude of $2.6 \mathrm{mV}$, a $10-90 \%$ rise of 0.43 msec, and half-width of 4.3 msec. $B$, Mean responses ( \pm SEM, dotted lines) of P8 $(n=8)$ and P39 GCs $(n=15)$ to $g_{\text {syn }} 8$ A or $g_{\text {syn }} 39$ at $-80 \mathrm{mV}$. The right-hand panel shows a histogram of EPSP peak amplitude, $10-90 \%$ rise-time, and half-width at the two ages. P39 EPSPs were significantly smaller and faster then P8 EPSPs. C, Mean responses of P39 GCs to injection of $g_{\text {syn }} 8 \mathrm{~A}$ and $g_{\text {syn }} 39$ (both $n=8$ ). Changing $g_{\text {syn }}$ affects only the amplitude and the rise of the EPSP.D, Mean responses of P8 and P39 GCs to $g_{\text {syn }} 39$ (both $n=$ 8). The different intrinsic properties of the two GCs affect only the rise and decay of the EPSP.

The action potential-evoked EPSP accelerates with age

Similar to the quantal EPSC, the AMPAR-mediated component of the evoked EPSC became faster with age. The 10-90\% rise time decreased from $0.29 \pm 0.04 \mathrm{msec}$ at P8 to $0.18 \pm 0.01$ msec at P39 ( $n=5$ and $4 ; p<0.05)$, and the major component of the current decay $\left(\tau_{\text {fast }}\right)$ was accelerated from $1.11 \pm 0.09$ $\mathrm{msec}$ at P8 to $0.77 \pm 0.05 \mathrm{msec}$ at P39 $(p<0.05)$, with no change in relative amplitude $\left(A_{\text {fast }} 83.1 \pm 2.2 \%\right.$ at $\mathrm{P} 8$ and $81.5 \pm 1.6 \%$ at P39) (Fig. $8 A$ ). The developmental speeding of the evoked EPSC decay $\left(\tau_{\text {fast }} \mathrm{P} 39 / \tau_{\text {fast }} \mathrm{P} 8\right.$ ratio, 0.69$)$ was comparable with that seen for the AMPAR-mediated quantal EPSC (0.65). This is consistent with the proposition (Wall et al., 2002) that an increased synchrony of transmitter release is unlikely to account for the overall speeding of the current. In fact, convolution of a Gaussian latency distribution (Silver et al., 1996) with the quantal waveform suggests that when the quantal decay is significantly slower than the width of the latency distribution, changes in latency affect the rise time but not the decay of the evoked EPSC, which is determined primarily by the time course of the quantal event (cf. Diamond and Jahr, 1995). Thus, in GCs the developmental speeding of the evoked EPSC decay is governed by the speeding of the underlying quantal events.

To investigate how the different components of the P8 and P39 evoked EPSCs influence the time course of the corresponding
EPSPs, we injected conductance waveforms derived from multiexponential fits to the population average AMPAR- and NMDARmediated currents into single-compartment passive models of GCs. An expanded view of the fitted currents at $+40 \mathrm{mV}$ is shown in Figure $8 \mathrm{~B}$. With respect to the AMPAR-mediated component, the NMDAR-mediated component exhibited a slow rise (10-90\% rise, $2.1 \pm 0.3 \mathrm{msec}$ at $\mathrm{P} 8$ and $2.3 \pm 0.6 \mathrm{msec}$ at P39) and a delayed onset, which increased with age $(0.58 \mathrm{msec}$ at $\mathrm{P} 8$ and $0.77 \mathrm{msec}$ at $\mathrm{P} 39)$. To produce NMDAR conductance waveforms appropriate for the respective resting membrane potentials of the P8 and P39 cells, we scaled the waveforms measured at $+40 \mathrm{mV}$, according to the expected voltage-dependent $\mathrm{Mg}^{2+}$ block (see Materials and Methods) (Fig. $8 C$, compare also $B, D$ ).

At resting membrane potential, the NMDAR-mediated conductance slowed the rise of the P8 EPSP $(+31 \%)$ and increased both its peak $(+15 \%)$ and its half-width $(+50 \%)$ (Fig. $8 C)$. In contrast, at P39 the EPSP was dominated by the AMPARmediated conductance (Fig. $8 C$ ), and the NMDAR conductance had little affect on the rise, peak, or width of the EPSP $(+1.5$, +0.4 , and $+12 \%$, respectively). The same qualitative difference was apparent when the EPSPs were compared at a common potential $(-80 \mathrm{mV})$. Overall, the EPSP produced by the P39 conductance had a faster rise and shorter duration than the EPSP produced by the P8 conductance (10-90\% rise, 0.7 vs $1.9 \mathrm{msec}$; half-width, 6.9 vs $16.2 \mathrm{msec}$ ) (Fig. $8 D$ ). The developmental 

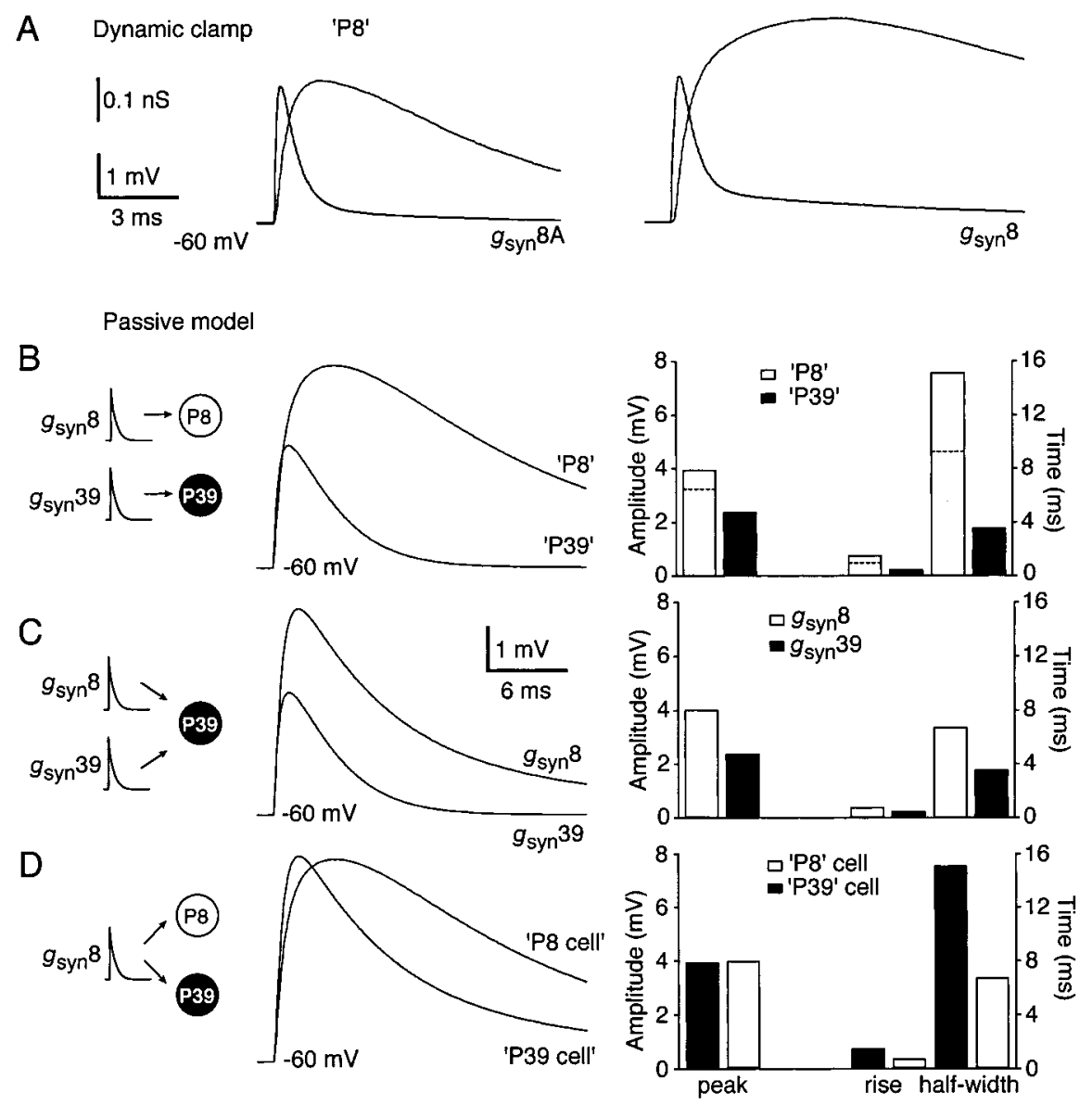

Figure 7. Effect of NMDARs on EPSPs evoked by conductance injection. $A$, Representative responses of $\mathrm{P} 8 \mathrm{GCS}(\mathrm{P} 8)$ to injection of synaptic conductance waveforms $\left(g_{\text {syn }} 8 \mathrm{~A}\right.$ and $g_{\text {syn }} 8$ ) at $-60 \mathrm{mV}$. The $g_{\text {syn }} 8 \mathrm{~A}$-induced EPSP had a peak amplitude of $4.6 \mathrm{mV}$, a $10-90 \%$ rise time of $2.34 \mathrm{msec}$, and half-width of $21.9 \mathrm{msec}$. The $g_{\text {syn }} 8$-induced EPSP had a peak amplitude of $3.2 \mathrm{mV}$, a $10-90 \%$ rise time of $0.82 \mathrm{msec}$, and half-width of $8.2 \mathrm{msec}$. B, EPSPs from single-compartment passive NEURON models of P8 and P39 GCs, evoked using $g_{\text {syn }} 8$ or $g_{\text {syn }} 39$. Model parameters were chosen to match properties of P8 GCs [diameter $12.7 \mu \mathrm{m}$ to give $C_{\text {in }}=4.0$ pF; specific membrane conductance $\left(G_{\mathrm{m}}\right) 1.56 \mathrm{e}^{-4} \mathrm{~S} / \mathrm{cm}^{2}$ to give $G_{\text {in }}=0.52 \mathrm{nS}$ ] and P39 $\mathrm{GCS}$ (diameter $10.3 \mu \mathrm{m}$ to give $C_{\text {in }}=$ $3.0 \mathrm{pF} ; G_{\mathrm{m}} 4.42 \mathrm{e}^{-4} \mathrm{~S} / \mathrm{cm}^{2}$ to give $G_{\text {in }}=1.47 \mathrm{nS}$ ). The right-hand panel shows a histogram of EPSP peak amplitude, $10-90 \%$ rise time, and half-width at the two ages. P39 EPSPs were significantly smaller and faster than P8 EPSPs. For comparison, the dashed lines in the P8 (open bars) indicate the results obtained with the AMPAR-mediated component alone. C, Responses from modeled P39 GCs to injection of $g_{\text {syn }} 8$ and $g_{\text {syn }} 39$. Changing $g_{\text {syn }}$ affects the amplitude, the rise, and the decay of the EPSP.D, Responses of modeled $\mathrm{P} 8$ and $\mathrm{P} 39 \mathrm{GCs}$ to $\mathrm{g}_{\mathrm{syn}} 8$. The different intrinsic properties of the two $\mathrm{GCs}$ affect only the rise and decay of the EPSP. Voltage and time calibrations in $A$ also apply to $B-D$.

change in the evoked EPSPs (rise - 65\%; half-width - 58\%) parallels that seen for the quantal EPSPs ( $-69 \%$ and $-77 \%)$, despite the presence of spillover after multiquantal release (DiGregorio et al., 2002).

The speeding of the somatic EPSP is predicted to play a critical role in the efficacy of spike generation, influencing the relationship between MF input and GC output (Gabbiani et al., 1994; Maex and Schutter, 1998) as well as the precision and reliability of spike timing (Fricker and Miles, 2000; Harsch and Robinson, 2000; Futai et al., 2001; Carter and Regehr, 2002).

\section{Determinants of EPSP-spike coupling}

To compare EPSP-spike coupling in immature and mature GCs, we injected a variable number of quanta (constructed from integer multiples of $g_{\text {syn }} 8, g_{\text {syn }} 8 \mathrm{~A}$, and $g_{\text {syn }} 39$ ) into P8 or P39 cells at their resting potentials to initiate a spike with a probability of $\sim 0.5(0.59 \pm 0.04,0.52 \pm 0.05$, and $0.57 \pm 0.05$, respectively; $n=$ $8-9 ; p>0.05)$. We considered this approach preferable to the stimulation of MFs, because it allowed us to examine the effect on spiking of different postsynaptic parameters, independently of stochastic variation in the release process. Because we were interested primarily in the effects caused by the speeding of the early phase of the EPSP, we adopted the simplified approach of using variable numbers of synchronous quantal events.

At both ages, conductance injection evoked only a single spike. In immature GCs, the spikes were triggered with a latency of $4.6 \pm 1.1 \mathrm{msec}$ and a temporal jitter (c.v. of latency) of $19.7 \pm 4.2 \%(n=$ 9). In mature GCs, both spike latency and jitter were reduced $(1.9 \pm 0.1 \mathrm{msec}$ and $10.5 \pm 0.8 \%$; both $p<0.05 ; n=9$ ) (Fig. $9 A)$. The efficacy of EPSP-spike coupling depends not only on the amplitude and shape of the EPSP, but also on the intrinsic spike generation mechanism of the cell. To investigate the importance of membrane properties to the development changes in spike latency and jitter, we stimulated P8 and P39 GCs with a common command waveform $\left(g_{\text {syn }} 8 \mathrm{~A}\right)$. Spikes were initiated with comparable latencies $(2.7 \pm 0.2$ vs $2.4 \pm 0.1 \mathrm{msec} ; p>0.05)$, but the jitter was significantly reduced in P39 GCs (17.3 \pm 3 vs $11.5 \pm 1.2 ; p<0.05 ; n=8$ and 6 ) (Fig. $9 B)$. We also compared the effect of different waveforms ( $g_{\text {syn }} 8 \mathrm{~A}$ and $\left.g_{\text {syn }} 39\right)$ in the same cell (P39). With $g_{\text {syn }} 8 \mathrm{~A}$, spikes were initiated with a longer latency than with $g_{\text {syn }} 39$ (2.4 \pm 0.1 vs $2.0 \pm 0.1 \mathrm{msec} ; p<$ $0.05)$, although the jitter was unaffected $(11.5 \pm 1.2$ vs $11.3 \pm 0.8 \% ; p>0.05 ; n=$ 6) (Fig. 9B). Comparison of Figure $9, B$ and $C$, shows that the developmental speeding of the AMPAR-EPSC significantly reduces the latency of EPSP-spike coupling, whereas the temporal jitter is set by the intrinsic membrane properties. Together, these results indicate that the speeding of the quantal EPSC and the changes in membrane properties converge to enhance the precision of spike generation.

\section{Discussion}

Our results illustrate how, during development of the MF-GC synapse, major changes in the intrinsic membrane properties of GCs and in the glutamate receptor-mediated synaptic conductance combine to increase the temporal precision of the EPSPspike coupling. This is likely to increase the fidelity with which afferent information is processed within the input layer of the cerebellar cortex.

\section{Relevance of developmental changes in quantal EPSC properties}

Quantal events are the fundamental building blocks for synaptic transmission at central synapses, and their basic properties are key determinants of information transfer. We found that at the MF-GC synapse the mean amplitude of quantal EPSCs did not 
change, but their kinetics became markedly faster, attributable to both a loss of the NMDAR-mediated component and a speeding of the AMPAR-mediated component. Because the duration of vesicular release after MF stimulation is brief relative to the quantal decay (Silver et al., 1996; DiGregorio et al., 2002; Wall et al., 2002), the properties of evoked EPSCs mostly reflect those of underlying quantal events, and the developmental speeding of their initial decay mirrors the speeding of the AMPAR-mediated component of the quantal events. Although spillover of glutamate onto AMPARs at neighboring MF synapses within a glomerulus (DiGregorio et al., 2002) and onto extrasynaptic NMDARs (see below) can influence the waveform of the evoked EPSC at mature synapses, such spillover may contribute significantly only at low frequencies of $\mathrm{MF}$ firing, when release probability is high. Thus the kinetics of the quantal EPSC are likely to remain a major determinant of the postsynaptic conductance waveform for physiologically relevant highfrequency inputs (van Kan et al., 1993), when release probability decreases and spillover becomes minimal (DiGregorio et al., 2002). Indeed, any activity-dependent reduction in release probability, by prefer-

entially reducing the spillover components, should allow the quantal parameters to determine the EPSP shape, thus preserving the temporal precision of spike generation.

\section{Impact of developmental changes in AMPAR-EPSCs}

The kinetics of the synaptic conductance have been shown to be important in shaping local EPSPs in thin dendrites (Rall, 1967; Jack et al., 1975; Hausser and Clark, 1997) and somatic EPSPs when synapses are located electrotonically close to the soma (Geiger et al., 1997; Trussell, 1997). In these cases the EPSP decay is governed primarily by the decay of the synaptic conductance; hence AMPAR-EPSC kinetics play a key role in determining the window for temporal summation of EPSPs. This contrasts with the situation in GCs, where the duration of the somatic EPSP is unaffected by developmental speeding in the AMPARmediated component of the EPSC. Instead, the speeding in AMPAR-EPSC kinetics affects specifically the early component of the EPSP, reducing its rise time and magnitude. These changes result in an increase of $\sim 50 \%$ in the number of synchronous quanta being required to reach spike threshold (our unpublished observation) and a reduction in the latency of EPSP-spike coupling.

\section{Significance of developmental loss of synaptic NMDARs}

In agreement with previous studies (Silver et al., 1992), our results show that quantal EPSCs at immature MF-GC synapses are mediated by both AMPARs and NMDARs. Although an unimpeded diffusion of glutamate could allow activation of highaffinity NMDARs located outside the synapse (Chen and Diamond, 2002), the submillisecond rise time of both current components suggests that the receptors are colocalized within the postsynaptic density. In mature GCs, NMDARs were activated

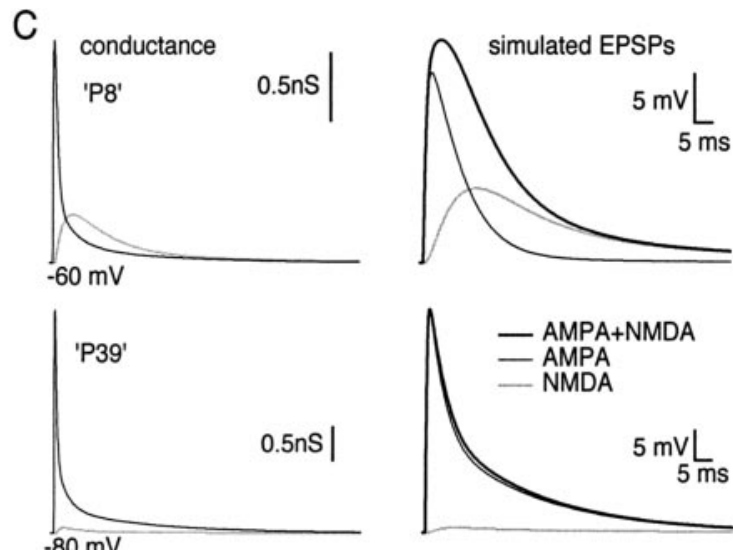

D

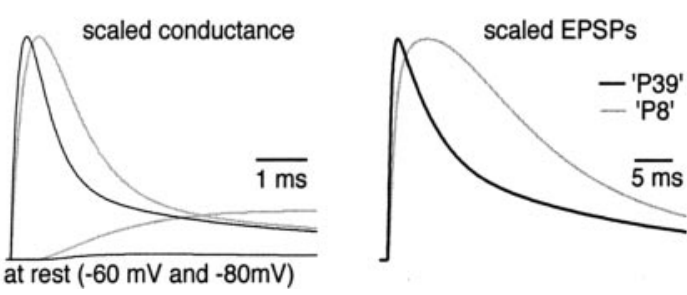

Figure 8. Action potential-evoked EPSCS and simulated EPSPs accelerate with age. A, Population average EPSCs recorded from A) recorded in AP5 $B$, Scaled multi-exponential fits of the evoked EPSCS shown in $A$. C Conductance waveforms with the

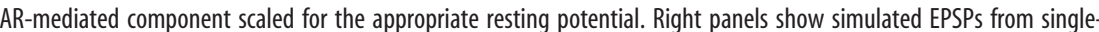
compartment passive NEURON models (details as in Fig. 7). D, Scaled conductance waveforms and corresponding dualcomponent EPSPs on expanded time scales.

after minimal stimulation of individual mossy fibers, but quantal EPSCs were mediated solely by AMPARs. This result strongly suggests that at these synapses functional AMPARs and NMDARs are not colocalized. In support of this finding, recent immunohistochemical observations from adult MF-GC synapses show that AMPAR subunits are located exclusively within postsynaptic densities (DiGregorio et al., 2002), whereas the majority of intraglomerular NMDAR subunits are located outside, or at the periphery of the synaptic specialization (Yamada et al., 2001), with a preponderance of labeling at intraglomerular attachment plaques (Petralia et al., 2002). Because the competitive inhibition of glutamate uptake does not increase AMPARmediated cross-talk between adjacent synapses within the glomerulus (DiGregorio et al., 2002), it is unlikely that differences in uptake underlie the developmental changes in NMDAR activation that we observe. Alterations in the glutamate content of vesicles, synaptic geometry, NMDAR affinity, or NMDAR gating could conceivably contribute (Jonas and Spruston, 1994; Conti and Weinberg, 1999), but the most likely explanation for our findings is that a redistribution of NMDARs occurs, such that AMPARs and NMDARs are spatially segregated in mature GCs. Thus, during development there is a switch from a situation in which a single quantum of transmitter activates both AMPARs and NMDARs to a situation in which the release of multiple vesicles is required to activate NMDARs. Because NMDARs would operate only during glutamate spillover, the level of presynaptic activity will determine their activation in mature GCs. Our data from mature GCs are comparable with recent observations showing that minimally evoked EPSCs in cerebellar stellate cells (Clark and Cull-Candy, 2002) and miniature EPSCs in retinal ganglion cells (Chen and Diamond, 2002) are mediated solely by AMPARs. However, in these cases the degree of glutamate 
A

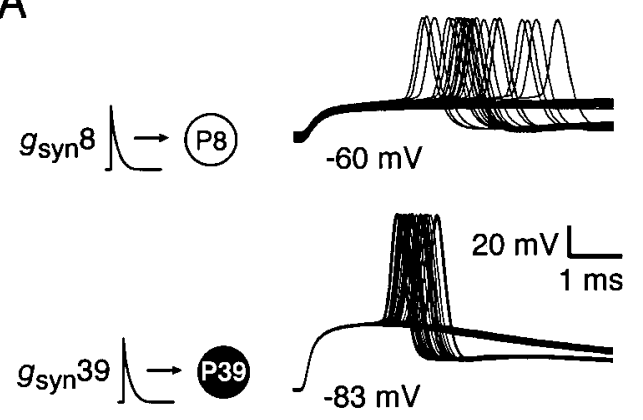

B

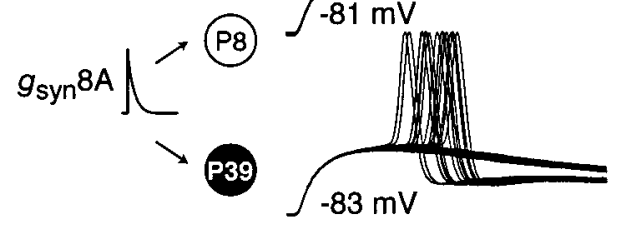

C
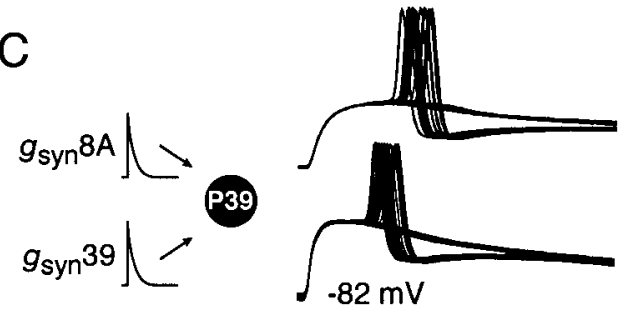
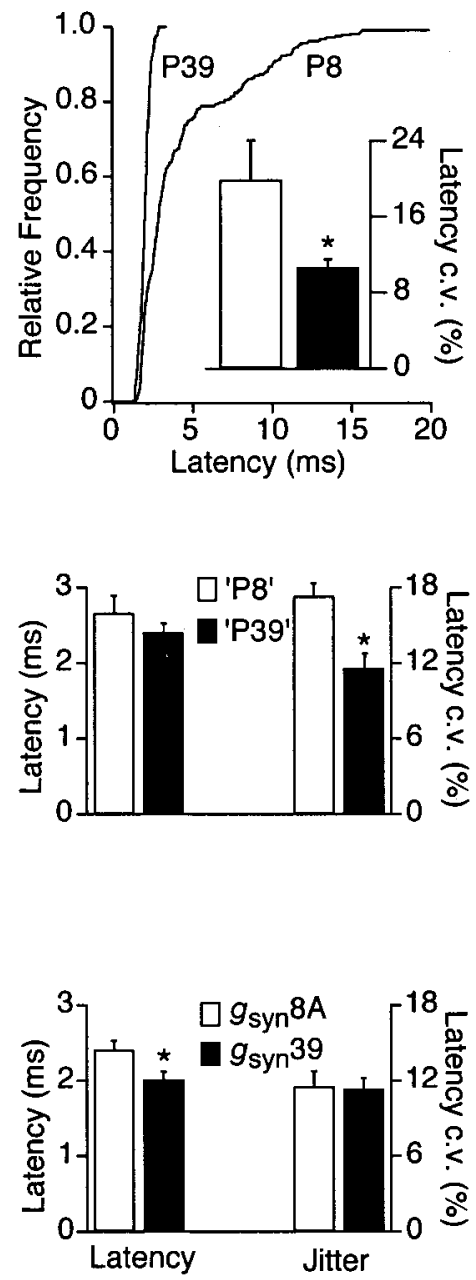

Figure 9. Developmental changes in EPSP-spike coupling. $A$, Representative examples of spikes induced in 'P8' and 'P39' GCs (P9 and P35) from their resting potentials, by the injection of multiple quanta. In each cell, by varying the number of quanta injected, the spiking probability was set close to 0.5 and was not significantly different between each test group. In the examples shown, spiking probability was 0.56 at P8 and 0.68 at P39. The right-hand panels summarize the spike latency and mean spike jitter ( $n=9$ at P8 and P39). The cumulative distributions of latency contain pooled data from all cells (an equal number of events from each cell) and are significantly different ( $p<0.05$; Kolmogorov-Smirnov test). In the histogram of spike jitter (Latency c.v.), the vertical error bars indicate SEM; ${ }^{*} p<0.05$. $B$, Representative examples of spikes induced by $g_{\text {syn }} 8 \mathrm{~A}$ injected into P8 and P39 GCs at their resting potentials. The right-hand panel shows a histogram of mean latency and jitter ( $n=8$ for P8 and 6 for P39). Error bars indicate SEM; ${ }^{*} p<0.05$. The relatively hyperpolarized resting potential of the $\mathrm{P} 8$ cell shown reflects the spread of the data, and at this age there was no correlation between resting potential and spike latency $(p=0.52$; Spearman rank order correlation) or spikejitter $(p=0.43)$. C, Representative examples of spikes induced by $g_{\text {syn }} 8 \mathrm{~A}$ and $g_{\text {syn }} 39$ injected into a single P39 cell. The right-hand panel shows a histogram of mean latency and jitter $(n=6)$.

spillover required to recruit extrasynaptic NMDARs differs. In stellate cells, high-frequency stimulation or activation of multiple presynaptic fibers is needed (Carter and Regehr, 2000; Clark and Cull-Candy, 2002), whereas in ganglion cells blockade of glutamate transport enables NMDAR activation during the largest miniature EPSCs (Chen and Diamond, 2002).

In immature GCs, because the NMDAR-mediated conductance is slower than the membrane time constant, this component affects not only the early part of the quantal EPSP but also its width. Loss of this NMDAR-mediated component in older animals clearly leads to smaller and faster quantal EPSPs, but it is also likely to modify the voltage dependence of transmission as well as the magnitude and spatial distribution of any glutamate receptor-mediated postsynaptic calcium entry. Together, these changes would be expected to alter the precision of spike generation (Harsch and Robinson, 2000; Futai et al., 2001; Maccaferri and Dingledine, 2002) and influence the expression of synaptic plasticity (D'Angelo et al., 1999). However, further studies will be required to determine the mechanism of any NMDAR redistribution (Carroll and Zukin, 2002; Losi et al., 2003; Wenthold et al., 2003) and its impact on MF-GC transmission under physiological conditions, when it is likely that multiple quanta are released in response to complex patterns of presynaptic activity.

The impact of developmental changes in intrinsic membrane properties

Synaptic integration depends on the duration of the EPSPs, because this determines the time window within which they summate to reach spike threshold. This is important because fast EPSPs allow neurons to behave as coincidence detectors, whereas neurons with slow EPSPs may behave as temporal integrators (Geiger et al., 1997; Trussell, 1997; Taschenberger and von Gersdorff, 2000). In mature GCs the decay of the quantal EPSP is governed primarily by the membrane time constant, and the increase in membrane conductance during development reduces the window for temporal summation. Accordingly, to attain spike threshold, synaptic events in mature GCs would have to occur at shorter intervals, increasing the requirement for coincident input. Several processes are thought to contribute to the increase in membrane conductance seen during GC development. These include a significant increase in both tonic GABA $_{\mathrm{A}} \mathrm{R}$-mediated (Brickley et al., 1996, 2001; Hamann et al., 2002) and potassium-dependent conductances (D’Angelo et al., 1994; Millar et al., 2000; Brickley et al., 2001). Both of these may be dynamically regulated (Brickley et al., 1996; Millar et al., 2000), and both will increase the temporal precision of spike generation, consistent with predictions from GC models (Gabbiani et al., 1994; Maex

and Schutter, 1998).

The developmental speeding of the EPSP decay, by reducing the duration of the EPSP plateau, should also increase temporal precision of EPSP-spike coupling in mature GCs (Fricker and Miles, 2000; Galarreta and Hestrin, 2001). Indeed, we have shown that the developmental change in intrinsic membrane properties reduced the temporal jitter of spike initiation. Whether the greater temporal jitter observed in immature GCs reflects only the slow EPSP decay, or is also affected by the immature state and lower number of sodium channels (D’Angelo et al., 1994), remains to be determined. Indeed, fewer sodium channels could mean that the timing of spike initiation will be more susceptible to the stochastic gating of the channels (Schneidman et al., 1998). In either case, any reduction in spike latency and variability would allow for a more accurate temporal coding of mossy fiber inputs in adult GCs. Moreover, with development, the hyperpo- 
larization of the resting membrane potential and the increased input conductance will dampen GC excitability and should result not only in a reduction of the window in which temporal summation can occur but also in an increase of the absolute number of quanta required to reach spike threshold, compared with the situation in immature GCs.

\section{Functional consequences for mature GCs}

As indicated above, the altered passive properties of mature GCs, brought about in part by the increased tonic component of GABA-mediated inhibition (Brickley et al., 1996), will act in concert with the developmental changes in the EPSC waveform to increase the likelihood that GCs fire only in response to closely timed MF inputs. In vivo, the firing of individual MFs is modulated over a wide range and may reach frequencies of several hundred Hertz (van Kan et al., 1993). Given that the conductance attributable to tonic $\mathrm{GABA}_{\mathrm{A}} \mathrm{R}$ activation increases with Golgi cell activity (Brickley et al., 1996) and should thus reflect the frequency of MF input, the developmental changes that we have described are likely to favor the sparse coding of MF input by GCs, which is thought to be necessary for coherent motor control (Marr, 1969; Tyrrell and Willshaw, 1992).

\section{References}

Akazawa C, Shigemoto R, Bessho Y, Nakanishi S, Mizuno N (1994) Differential expression of five $N$-methyl-D-aspartate receptor subunit mRNAs in the cerebellum of developing and adult rats. J Comp Neurol 347:150-160.

Baude A, Molnar E, Latawiec D, McIlhinney RA, Somogyi P (1994) Synaptic and nonsynaptic localization of the GluR1 subunit of the AMPA-type excitatory amino acid receptor in the rat cerebellum. J Neurosci 14:2830-2843.

Bekkers JM, Stevens CF (1989) NMDA and non-NMDA receptors are colocalized at individual excitatory synapses in cultured rat hippocampus. Nature 341:230-233.

Brenowitz S, Trussell LO (2001) Maturation of synaptic transmission at end-bulb synapses of the cochlear nucleus. J Neurosci 21:9487-9498.

Brickley SG, Cull-Candy SG, Farrant M (1996) Development of a tonic form of synaptic inhibition in rat cerebellar granule cells resulting from persistent activation of GABA A receptors. J Physiol (Lond) 497:753-759.

Brickley SG, Revilla V, Cull-Candy SG, Wisden W, Farrant M (2001) Adaptive regulation of neuronal excitability by a voltage-independent potassium conductance. Nature 409:88-92.

Carroll RC, Zukin RS (2002) NMDA-receptor trafficking and targeting: implications for synaptic transmission and plasticity. Trends Neurosci 25:571-577.

Carter AG, Regehr WG (2000) Prolonged synaptic currents and glutamate spillover at the parallel fiber to stellate cell synapse. J Neurosci 20:4423-4434.

Carter AG, Regehr WG (2002) Quantal events shape cerebellar interneuron firing. Nat Neurosci 5:1309-1318.

Cathala L, Misra C, Cull-Candy S (2000) Developmental profile of the changing properties of NMDA receptors at cerebellar mossy fiber-granule cell synapses. J Neurosci 20:5899-5905.

Chen S, Diamond JS (2002) Synaptically released glutamate activates extrasynaptic NMDA receptors on cells in the ganglion cell layer of rat retina. J Neurosci 22:2165-2173.

Clark BA, Cull-Candy SG (2002) Activity-dependent recruitment of extrasynaptic NMDA receptor activation at an AMPA receptor-only synapse. J Neurosci 22:4428-4436.

Conti F, Weinberg RJ (1999) Shaping excitation at glutamatergic synapses. Trends Neurosci 22:451-458.

D’Angelo E, Rossi P, De Filippi G, Magistretti J, Taglietti V (1994) The relationship between synaptogenesis and expression of voltagedependent currents in cerebellar granule cells in situ. J Physiol (Paris) 88:197-207.

D’Angelo E, De Filippi G, Rossi P, Taglietti V (1995) Synaptic excitation of individual rat cerebellar granule cells in situ: evidence for the role of NMDA receptors. J Physiol (Lond) 484:397-413.
D’Angelo E, Rossi P, Armano S, Taglietti V (1999) Evidence for NMDA and mGlu receptor-dependent long-term potentiation of mossy fiber-granule cell transmission in rat cerebellum. J Neurophysiol 81:277-287.

De Schutter E, Bjaalie JG (2001) Coding in the granular layer of the cerebellum. Prog Brain Res 130:279-296.

Diamond JS, Jahr CE (1995) Asynchronous release of synaptic vesicles determines the time course of the AMPA receptor-mediated EPSC. Neuron 15:1097-1107.

DiGregorio D, Nusser Z, Silver R (2002) Spillover of glutamate onto synaptic AMPA receptors enhances fast transmission at a cerebellar synapse. Neuron 35:521-533.

Edmonds B, Gibb AJ, Colquhoun D (1995) Mechanisms of activation of glutamate receptors and the time course of excitatory synaptic currents. Annu Rev Physiol 57:495-519.

Farrant M, Feldmeyer D, Takahashi T, Cull-Candy SG (1994) NMDAreceptor channel diversity in the developing cerebellum. Nature 368:335-339.

Fricker D, Miles R (2000) EPSP amplification and the precision of spike timing in hippocampal neurons. Neuron 28:559-569.

Futai K, Okada M, Matsuyama K, Takahashi T (2001) High-fidelity transmission acquired via a developmental decrease in NMDA receptor expression at an auditory synapse. J Neurosci 21:3342-3349.

Gabbiani F, Midtgaard J, Knopfel T (1994) Synaptic integration in a model of cerebellar granule cells. J Neurophysiol 72:999-1009.

Galarreta M, Hestrin S (2001) Spike transmission and synchrony detection in networks of GABAergic interneurons. Science 292:2295-2299.

Geiger JR, Lubke J, Roth A, Frotscher M, Jonas P (1997) Submillisecond AMPA receptor-mediated signaling at a principal neuron-interneuron synapse. Neuron 18:1009-1023.

Gentet LJ, Stuart GJ, Clements JD (2000) Direct measurement of specific membrane capacitance in neurons. Biophys J 79:314-320.

Hamann M, Rossi DJ, Attwell D (2002) Tonic and spillover inhibition of granule cells control information flow through cerebellar cortex. Neuron 33:625-633.

Hamori J, Somogyi J (1983) Differentiation of cerebellar mossy fiber synapses in the rat: a quantitative electron microscope study. J Comp Neurol 220:365-377.

Harsch A, Robinson HP (2000) Postsynaptic variability of firing in rat cortical neurons: the roles of input synchronization and synaptic NMDA receptor conductance. J Neurosci 20:6181-6192.

Hashimoto K, Fukaya M, Qiao X, Sakimura K, Watanabe M, Kano M (1999) Impairment of AMPA receptor function in cerebellar granule cells of ataxic mutant mouse stargazer. J Neurosci 19:6027-6036.

Hausser M, Clark BA (1997) Tonic synaptic inhibition modulates neuronal output pattern and spatiotemporal synaptic integration. Neuron 19:665-678.

Hines ML, Carnevale NT (1997) The NEURON simulation environment. Neural Comput 9:1179-1209.

Isaac JT, Nicoll RA, Malenka RC (1995) Evidence for silent synapses: implications for the expression of LTP. Neuron 15:427-434.

Jack JJ, Redman SJ (1971) The propagation of transient potentials in some linear cable structures. J Physiol (Lond) 215:283-320.

Jack JJB, Noble D, Tsien RW (1975) Electric current flow in excitable cells. Oxford: Clarendon.

Jonas P, Spruston N (1994) Mechanisms shaping glutamate-mediated excitatory postsynaptic currents in the CNS. Curr Opin Neurobiol 4:366-372.

Jones KA, Baughman RW (1991) Both NMDA and non-NMDA subtypes of glutamate receptors are concentrated at synapses on cerebral cortical neurons in culture. Neuron 7:593-603.

Kadotani H, Hirano T, Masugi M, Nakamura K, Nakao K, Katsuki M, Nakanishi S (1996) Motor discoordination results from combined gene disruption of the NMDA receptor NR2A and NR2C subunits, but not from single disruption of the NR2A or NR2C subunit. J Neurosci 16:7859-7867.

Kharazia VN, Phend KD, Rustioni A, Weinberg RJ (1996) EM colocalization of AMPA and NMDA receptor subunits at synapses in rat cerebral cortex. Neurosci Lett 210:37-40.

Kuba H, Koyano K, Ohmori H (2002) Development of membrane conductance improves coincidence detection in the nucleus laminaris of the chicken. J Physiol (Lond) 540:529-542.

Liao D, Hessler NA, Malinow R (1995) Activation of postsynaptically silent 
synapses during pairing-induced LTP in CA1 region of hippocampal slice. Nature 375:400-404.

London M, Schreibman A, Hausser M, Larkum ME, Segev I (2002) The information efficacy of a synapse. Nat Neurosci 5:332-340.

Losi G, Prybylowski K, Fu Z, Luo J, Wenthold RJ, Vicini S (2003) PSD-95 regulates NMDA receptors in developing cerebellar granule neurons of the rat. J Physiol (Lond) 548:21-29.

Maccaferri G, Dingledine R (2002) Control of feedforward dendritic inhibition by NMDA receptor-dependent spike timing in hippocampal interneurons. J Neurosci 22:5462-5472.

Maex R, Schutter ED (1998) Synchronization of Golgi and granule cell firing in a detailed network model of the cerebellar granule cell layer. J Neurophysiol 80:2521-2537.

Marr D (1969) A theory of cerebellar cortex. J Physiol (Lond) 202:437-470.

McCormick DA, Prince DA (1987) Post-natal development of electrophysiological properties of rat cerebral cortical pyramidal neurones. J Physiol (Lond) 393:743-762.

Millar JA, Barratt L, Southan AP, Page KM, Fyffe RE, Robertson B, Mathie A (2000) A functional role for the two-pore domain potassium channel TASK-1 in cerebellar granule neurons. Proc Natl Acad Sci USA 97:3614-3618.

Monyer H, Burnashev N, Laurie DJ, Sakmann B, Seeburg PH (1994) Developmental and regional expression in the rat brain and functional properties of four NMDA receptors. Neuron 12:529-540.

Mosbacher J, Schoepfer R, Monyer H, Burnashev N, Seeburg PH, Ruppersberg JP (1994) A molecular determinant for submillisecond desensitization in glutamate receptors. Science 266:1059-1062.

Palay SL, Chan-Palay V (1974) Cerebellar cortex: cytology and organization. Berlin: Springer.

Petralia RS, Esteban JA, Wang YX, Partridge JG, Zhao HM, Wenthold RJ, Malinow R (1999) Selective acquisition of AMPA receptors over postnatal development suggests a molecular basis for silent synapses. Nat Neurosci 2:31-36.

Petralia RS, Wang YX, Wenthold RJ (2002) NMDA receptors and PSD-95 are found in attachment plaques in cerebellar granular layer glomeruli. Eur J Neurosci 15:583-587.

Racca C, Stephenson FA, Streit P, Roberts JD, Somogyi P (2000) NMDA receptor content of synapses in stratum radiatum of the hippocampal CA1 area. J Neurosci 20:2512-2522.

Rall W (1967) Distinguishing theoretical synaptic potentials computed for different soma-dendritic distributions of synaptic input. J Neurophysiol 30:1138-1168.

Ramon y Cajal S (1995) Histology of the nervous system of man and vertebrates. New York: Oxford UP.

Reyes A (2001) Influence of dendritic conductances on the input-output properties of neurons. Annu Rev Neurosci 24:653-675.

Ripellino JA, Neve RL, Howe JR (1998) Expression and heteromeric interactions of non- $N$-methyl-D-aspartate glutamate receptor subunits in the developing and adult cerebellum. Neuroscience 82:485-497.

Robinson HP, Kawai N (1993) Injection of digitally synthesized synaptic conductance transients to measure the integrative properties of neurons. J Neurosci Methods 49:157-165.

Rumbaugh G, Vicini S (1999) Distinct synaptic and extrasynaptic NMDA receptors in developing cerebellar granule neurons. J Neurosci 19:10603-10610.

Schneidman E, Freedman B, Segev I (1998) Ion channel stochasticity may be critical in determining the reliability and precision of spike timing. Neural Comput 10:1679-1703.
Shi SH, Hayashi Y, Petralia RS, Zaman SH, Wenthold RJ, Svoboda K, Malinow R (1999) Rapid spine delivery and redistribution of AMPA receptors after synaptic NMDA receptor activation. Science 284:1811-1816.

Silver RA, Traynelis SF, Cull-Candy SG (1992) Rapid-time-course miniature and evoked excitatory currents at cerebellar synapses in situ. Nature 355:163-166.

Silver RA, Cull-Candy SG, Takahashi T (1996) Non-NMDA glutamate receptor occupancy and open probability at a rat cerebellar synapse with single and multiple release sites. J Physiol (Lond) 494:231-250.

Singer JH, Talley EM, Bayliss DA, Berger AJ (1998) Development of glycinergic synaptic transmission to rat brain stem motoneurons. J Neurophysiol 80:2608-2620.

Smith TC, Wang LY, Howe JR (2000) Heterogeneous conductance levels of native AMPA receptors. J Neurosci 20:2073-2085.

Takahashi T, Feldmeyer D, Suzuki N, Onodera K, Cull-Candy SG, Sakimura K, Mishina M (1996) Functional correlation of NMDA receptor $\epsilon$ subunits expression with the properties of single-channel and synaptic currents in the developing cerebellum. J Neurosci 16:4376-4382.

Takahashi T, Svoboda K, Malinow R (2003) Experience strengthening transmission by driving AMPA receptors into synapses. Science 299:1585-1588.

Takumi Y, Ramirez-Leon V, Laake P, Rinvik E, Ottersen OP (1999) Different modes of expression of AMPA and NMDA receptors in hippocampal synapses. Nat Neurosci 2:618-624.

Taschenberger H, von Gersdorff H (2000) Fine-tuning an auditory synapse for speed and fidelity: developmental changes in presynaptic waveform, EPSC kinetics, and synaptic plasticity. J Neurosci 20:9162-9173.

Taschenberger H, Leao RM, Rowland KC, Spirou GA, von Gersdorff $\mathrm{H}$ (2002) Optimizing synaptic architecture and efficiency for highfrequency transmission. Neuron 36:1127-1143.

Trussell LO (1997) Cellular mechanisms for preservation of timing in central auditory pathways. Curr Opin Neurobiol 7:487-492.

Tyrrell T, Willshaw D (1992) Cerebellar cortex: its simulation and the relevance of Marr's theory. Philos Trans R Soc Lond B Biol Sci 336:239-257.

Umemiya M, Senda M, Murphy TH (1999) Behaviour of NMDA and AMPA receptor-mediated miniature EPSCs at rat cortical neuron synapses identified by calcium imaging. J Physiol (Lond) 521:113-122.

van Kan PL, Gibson AR, Houk JC (1993) Movement-related inputs to intermediate cerebellum of the monkey. J Neurophysiol 69:74-94.

Wall MJ, Usowicz MM (1998) Development of the quantal properties of evoked and spontaneous synaptic currents at a brain synapse. Nat Neurosci 1:675-682.

Wall MJ, Robert A, Howe JR, Usowicz MM (2002) The speeding of EPSC kinetics during maturation of a central synapse. Eur J Neurosci 15:785-797.

Watanabe D, Inokawa H, Hashimoto K, Suzuki N, Kano M, Shigemoto R, Hirano T, Toyama K, Kaneko S, Yokoi M, Moriyoshi K, Suzuki M, Kobayashi K, Nagatsu T, Kreitman RJ, Pastan I, Nakanishi S (1998) Ablation of cerebellar Golgi cells disrupts synaptic integration involving GABA inhibition and NMDA receptor activation in motor coordination. Cell 95:17-27.

Wenthold RJ, Prybylowski K, Standley S, Sans N, Petralia RS (2003) Trafficking of NMDA receptors. Annu Rev Pharmacol Toxicol 43:335-358.

Yamada K, Fukaya M, Shimizu H, Sakimura K, Watanabe M (2001) NMDA receptor subunits GluR $\epsilon 1$, GluR $\epsilon 3$ and GluR $\zeta 1$ are enriched at the mossy fibre-granule cell synapse in the adult mouse cerebellum. Eur J Neurosci 13:2025-2036. 